\title{
Evaluation of Various Dynamic Issues during Transient Operation of Turbocharged Diesel Engine with Special Reference to Friction Development
}

\author{
C.D. Rakopoulos, E.G. Giakoumis and A.M. Dimaratos \\ School of Mechanical Engineering, National Technical University of Athens
}

Copyright @ 2007 SAE International

\begin{abstract}
The modeling of transient turbocharged diesel engine operation appeared in the early seventies and continues to be in the focal point of research, due to the importance of transient response in the everyday operating conditions of engines. The majority of research has focused so far on issues concerning thermodynamic modeling, as these directly affect heat release predictions and consequently performance and pollutants emissions. On the other hand, issues concerning the dynamics of transient operation are often disregarded or over-simplified, possibly for the sake of speeding up program execution time. In the present work, an experimentally validated transient diesel engine simulation code is used to study and evaluate the importance of such dynamic issues. First of all, the development of various forces (piston, connecting rod, crank and main crankshaft bearings) is computed and illustrated in order to evaluate the importance of abrupt load increases on the bearings durability. The usual approximation of the connecting rod being considered as equivalent to two masses (one reciprocating with the piston and the other rotating with the crank) is put into test. The same holds true for another usual assumption, i.e. the crankshaft being considered as sufficiently rigid. In this work, the engine crankshaft is analyzed in detail with the instantaneous torsional angle between engine and load taken into account. Thus, details are provided concerning the development of crankshaft torsional deformation during transients. The main part of the paper focuses on the development and contribution of various friction components during turbocharged diesel engine transients. This is accomplished via the use of a recently proposed detailed friction model. Mean fmep (friction mean effective pressure) modeling is found to considerably underestimate actual friction around firing TDC, leading to lower speed droops for abrupt load increases. The piston rings assembly contribution is dominant for the particular engine, due to its high number of piston rings and its relatively low crankshaft speed. The model can be used to investigate such interesting cases as the effect of engine oil temperature
\end{abstract}

on engine transient response, or the variation of oil film thickness during a cycle or a transient event.

\section{INTRODUCTION}

The turbocharged diesel engine is nowadays the most preferred prime mover in medium and medium-large units applications (truck driving, land traction, ship propulsion, electrical generation). Moreover, it continuously increases its share in the highly competitive automotive market, owing to its reliability that is combined with excellent fuel efficiency. Nonetheless, its transient operation is often linked with off-design (e.g. turbocharger lag) and consequently non-optimum performance, pointing out the significance of proper interconnection between engine, governor-controller, fuel pump, turbocharger and load.

During the last three decades, diesel engine simulation and experimental investigation have paved the way for an in-depth study of transient operation [1-7]. However, the majority of research has focused so far on issues concerning thermodynamic modeling because of their direct impact on heat release prediction and consequently performance and pollutants emissions. On the other hand, issues concerning engine dynamics during transient operation are often disregarded or oversimplified for the sake of possibly speeding up computer program execution time.

Such notable dynamic issues that contribute to the nonlinearity of diesel engine (transient) operation are:

- The crankshaft torsional deformation owing to the different magnitude of instantaneous torque induced by the engine and load,

- The development of engine friction as, at the moment, the use of mean fmep relations in transient simulations prohibits any in depth analysis,

- The development of the various forces of the slidercrank mechanism that may lead to considerable stress of the engine bearings, and 
- The movement of the connecting rod, which, although being a rigid body, is usually approximated by two masses, one reciprocating with the piston and the other rotating with the crank.

Engine friction is the most important of the abovementioned dynamic issues. It is a well known fact that friction torque varies significantly during the 720 degrees crank angle of a four-stroke engine cycle $[8,9]$; its magnitude compared to brake torque is not negligible, particularly at low loads where the most demanding transient events commence. Its modeling is, however, difficult due to the interchanging nature of lubrication (boundary, mixed, hydrodynamic) and the large number of components, i.e. piston rings, piston skirt, loaded bearings, valve train and auxiliaries that cannot be easily isolated, experimentally investigated, and studied separately even at steady-state conditions $[10,11]$. Moreover, during transient operation, it is believed that friction is characterized by non steady-state behavior, differentiating engine response and performance when compared to the corresponding steady-state values, i.e. at the same engine speed and fueling conditions [7]. For example, Winterbone and Tennant [12] assumed that friction torque should be generally overestimated by some percentage during the transient event to account for the peculiarities of transient operation. Rakopoulos and Giakoumis [7] investigated this aspect increasing the transient friction torque by a factor proportional to the instantaneous crankshaft deceleration.

Friction modeling in transient simulation codes has, almost, always in the past (with a few notable exceptions [13-18]) been applied in the form of mean fmep relations, remaining constant for every degree crank angle in each cycle in the model simulation; thus, the effect of real friction torque on the model's predictive capabilities was limited. This is primarily attributed to the scarcity-complexity of detailed, per degree crank angle, friction simulations. It is also, probably, due to the fact that friction modeling does not affect heat release rate but only the crankshaft energy balance; the latter is, nonetheless, essential for correct transient predictions. Consequently, correct friction modeling does not diversify the interior engine indicating properties and thus exhaust emissions. However, by defining the magnitude of engine mechanical losses, it directly affects brake specific fuel consumption.

The sensitivity of transient operation predictions to friction modeling errors has been investigated by Watson [1], who showed that a (rather exaggerated) $50 \%$ overestimation in friction torque could lead to an almost equal increase in predicted final engine speed drop. He also proposed application of the mean fmep equation at each computational step rather than each cycle. Gardner and Henein [15], as regards engine starting, and Tuccilo et al. [16] gave some preliminary transient results adopting the semi-empirical RezekaHenein [19] friction model. Ciulli et al. [18] developed 3 friction models of various complexity and incorporated them in a simplified dynamic simulation. The objective was to determine which of these models captured most effectively transient engine operation. Past work by the present research group $[13,20]$, incorporating the more fundamental Taraza et al. [21] friction model in a transient simulation code, revealed that mean fmep modeling can underestimate the prediction of engine speed response by up to $8 \%$. In all the works where analytical friction modeling was incorporated into the simulation code, this was, mainly, accomplished in an attempt to predict engine transient response more accurately. However, no comparison was presented with the results obtained using fmep relations; moreover, no attempt was made to study the development of friction components during transients, possibly with the exception of a few results presented in [18].

Another important aspect of engine dynamic operation is that both instantaneous torque and crankshaft speed fluctuate considerably during an engine cycle (even at steady-state conditions), as a result of the cyclic nature of gas pressure and inertia forces. This, in conjunction with the fact that load transients constitute a highly adverse engine operating condition that can lead to early material failure [7], urged the present research group to consider the following two aspects of dynamic operation in their transient investigations:

- The development of various forces, i.e. piston, connecting rod small and big end bearings, crank pin, crank journal and main crankshaft bearings; by so doing, it was possible to quantify the importance of abrupt load increases on the bearings durability,

- The study of crankshaft torsional deformation during load transients, where a considerable deficit of torque is observed during the early cycles of the event. In the majority of the previous simulations, the crankshaft had been assumed sufficiently rigid, so that no differentiation was taken into account between engine and load torsional angles.

In order to fulfil the above goals, an experimentally validated, non-linear, transient diesel engine simulation code that follows the filling and emptying approach is used; this incorporates some important features to account for the peculiarities of transient operation. Improved relations concerning fuel injection, combustion, dynamic analysis, heat transfer to the cylinder walls, and multi-cylinder engine operation during transient response have been developed, which contribute to an in-depth modeling $[6,7,13,20]$.

The fundamental friction model proposed by Taraza et al. [21] is used, to analytically simulate each friction component; direct comparison is also made with the results obtained using the common 'fmep approach'. This friction model separates friction torque into four terms, allowing for detailed modeling at each degree crank angle. The obvious advantage of working with a detailed friction model, over the mean fmep relations, is the fact that it was made possible to estimate the 
contribution of each friction component during a cycle and study its development during a transient event.

The analysis carried out will be given in a series of diagrams that depict the response of engine speed, forces of the kinematic mechanism, friction components, and torsional deformation of the crankshaft. The development of an interesting engine parameter, i.e. oil film thickness, as well as the effect of oil temperature on engine transient response, will also be studied. Owing to the narrow speed range of the engine in hand, mainly load increases under constant governor setting are investigated, which, nonetheless, play a significant role in the European Transient Cycles of heavy duty vehicles. A sensitivity analysis will also be carried out, in order to establish whether incorporation of a detailed friction, crankshaft or connecting rod sub-model leads in more accurate predictions of transient engine response.

\section{SIMULATION ANALYSIS}

The block diagram of the simulation model developed is illustrated in Fig. 1. A brief description of the equations involved will be presented in the next sub-sections.

\section{GENERAL PROCESS DESCRIPTION}

The present analysis does not, at the moment, include predictions of exhaust gas emissions and on the other side deals with transient operation calculations on a ${ }^{\circ} \mathrm{CA}$ (degree crank angle) basis. Therefore, a single-zone model following the filling and emptying approach is used for the thermodynamic processes evaluation. It is felt that this approach is the best compromise between accuracy and limited PC program execution time [7]. The fuel is dodecane $\left(\mathrm{C}_{12} \mathrm{H}_{26}\right)$ with a lower heating value, $L H V=42,500 \mathrm{~kJ} / \mathrm{kg}$. Perfect gas behavior is assumed. Polynomial expressions are used for the species considered, concerning the evaluation of internal energy and specific heat capacities for first-law applications to the engine cylinder contents [8]. The species considered are: $\mathrm{O}_{2}, \mathrm{~N}_{2}, \mathrm{CO}_{2}, \mathrm{H}_{2} \mathrm{O}$ and $\mathrm{CO}$; the latter is taken into account, using the corresponding chemical equilibrium scheme, only when the mixture is rich $(\Phi>1)$ and for gas temperatures exceeding $1400 \mathrm{~K}$, as for example occurs during the early cycles of the transient event where the turbocharger lag is prominent [7].

For heat release rate predictions, the fundamental model proposed by Whitehouse and Way [22] is used. Especially during transients, the constant $\mathrm{K}$ in the (dominant) preparation rate equation of the model is correlated with the Sauter mean diameter (SMD) of the fuel droplets, through a formula of the type $\mathrm{K} \propto(1 / \mathrm{SMD})^{2.5}$ [23]. The effect of fuel-air equivalence

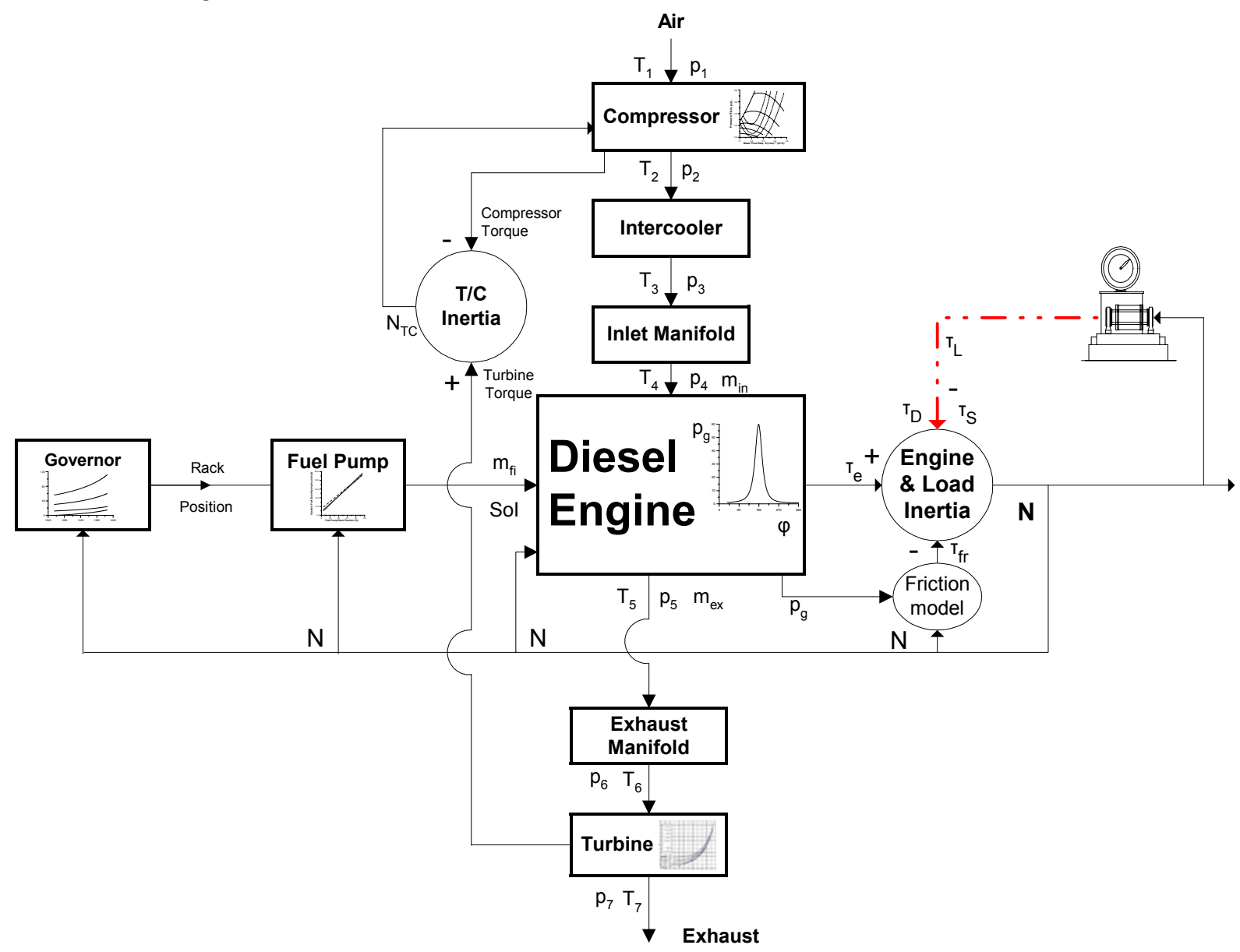

Fig.1. Block diagram of the developed simulation code 
ratio $\Phi$ is also taken into account through the following correction equation for the activation constant 'act',

$$
\text { act }=\operatorname{act}_{\mathrm{o}} \cdot\left(\Delta \Phi / \Phi_{\mathrm{o}}\right)^{\mathrm{c}}
$$

with the subscript 'o' denoting reference conditions.

The improved model of Annand [24] is used to simulate heat loss $Q_{L}$ to the cylinder walls,

$$
\frac{d Q_{L}}{d t}=A\left\{\frac{k_{g}}{D} R^{b}\left[a\left(T_{g}-T_{w}\right)+\frac{a^{\prime}}{\omega} \frac{d T_{g}}{d t}\right]+c\left(T_{g}^{4}-T_{w}^{4}\right)\right\}
$$

where $a, a$, $b$ and $c$ are constants evaluated after experimental matching at steady-state conditions, $A=2 A_{\text {pist }}+A^{\prime}$, with $A_{\text {pist }}=\left(\pi D^{2} / 4\right)$ the piston cross section area, $A^{\prime}=\pi D x$, with $x$ the instantaneous cylinder height in contact with the gas (see Eq. (3) below). Further, $\mathrm{k}_{\mathrm{g}}$ is the gas thermal conductivity, and the Reynolds number $\mathrm{Re}$ is calculated with a characteristic speed derived from a $k-\varepsilon$ turbulence model and a characteristic length equal to the piston diameter. During transient operation, the thermal inertia of the cylinder wall is taken into account, using a detailed heat transfer scheme that models the temperature distribution from the gas to the cylinder wall up to the coolant (convection from gas to internal wall surface and from external wall surface to coolant, and conduction across the cylinder wall).

\section{BEARINGS LOADING}

At each instant of time, the piston displacement from the top dead center (TDC) position is determined by [8]

$$
x(\varphi)=r(1-\cos \varphi)+L_{\text {rod }}\left(1-\sqrt{1-\lambda^{2} \sin ^{2} \varphi}\right)
$$

where $r$ is the crank radius, $\lambda=r / L_{\text {rod }}$ with $L_{\text {rod }}$ the connecting rod length (see also Fig. 2), and the crank angle $\varphi$ is measured from the TDC position. Differentiating the above equation with respect to time, we get the instantaneous piston velocity

$$
u_{\text {pist }}(\varphi)=\omega r \sin \varphi\left(1+\frac{\lambda \cos \varphi}{\sqrt{1-\lambda^{2} \sin ^{2} \varphi}}\right)
$$

while differentiating once again with respect to time, we get the instantaneous piston acceleration

$$
\mathrm{b}(\varphi)=\omega^{2} \mathrm{r}\left(\cos \varphi+\lambda \frac{\cos 2 \varphi+\lambda^{2} \sin ^{4} \varphi}{\left(1-\lambda^{2} \sin ^{2} \varphi\right)^{3 / 2}}+\frac{1}{\omega^{2}} \varepsilon \frac{\mathrm{u}_{\text {pist }}}{\mathrm{r} \omega}\right)
$$

The last term on the right hand side of Eq. (4b) takes into account the crank's angular acceleration ' $\varepsilon$ ' in the piston acceleration.

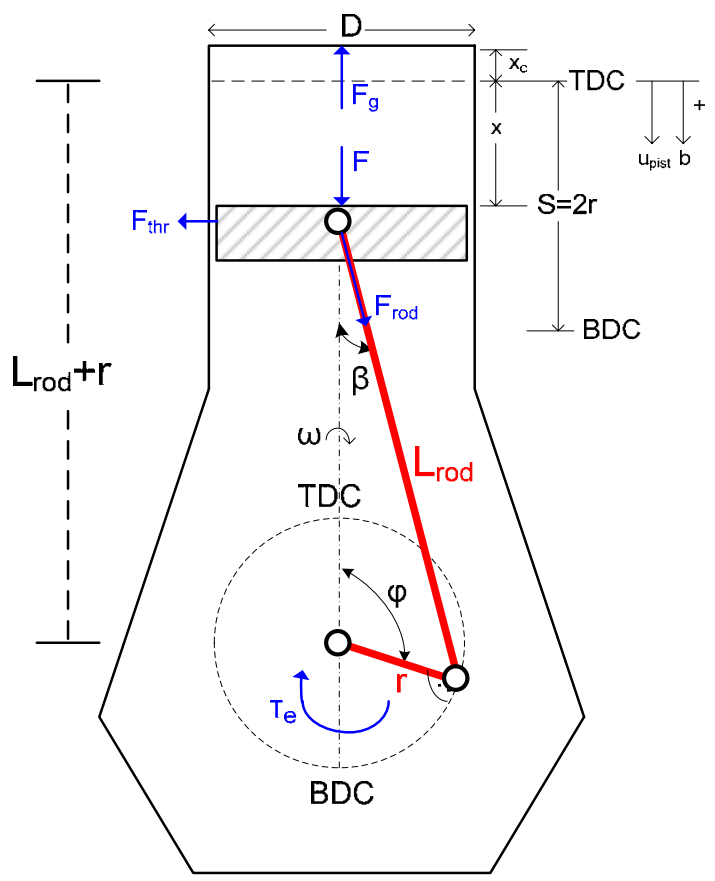

Fig. 2. Schematic diagram of slider crank mechanism identifying the various forces developed

The loading of the bearings can then be computed from the following equations, with reference to Fig. $3[25,26]$

$$
\begin{gathered}
\mathrm{B}_{0 \mathrm{x}}=-\mathrm{m}_{\text {rod.l }} \cdot \mathrm{b} \sin \beta \\
\mathrm{B}_{0 \mathrm{y}}=-\frac{\mathrm{F}(\varphi)}{\cos \beta}-\mathrm{m}_{\text {rod. } \mathrm{l}} \cdot \mathrm{b} \cos \beta
\end{gathered}
$$

for the connecting rod small end bearing,

$$
\begin{gathered}
\mathrm{B}_{1 \mathrm{x}}=-\mathrm{m}_{\text {rod.r }} \cdot \mathrm{u}_{\text {pist }} \cdot \omega \cdot \cos \beta \\
\mathrm{B}_{1 \mathrm{y}}=\frac{\mathrm{F}(\varphi)}{\cos \beta}-\mathrm{m}_{\text {rod.r }} \cdot \mathrm{r} \omega^{2} \cos (\varphi+\beta)
\end{gathered}
$$

for the connecting rod big end bearing,

$$
\begin{gathered}
B_{2 x}=\frac{F(\varphi)}{\cos \beta} \sin (\varphi+\beta) \\
B_{2 y}=-\frac{F(\varphi)}{\cos \beta} \cos (\varphi+\beta)+m_{\text {rod.r }} \cdot r \omega^{2}
\end{gathered}
$$

for the crank pin, 


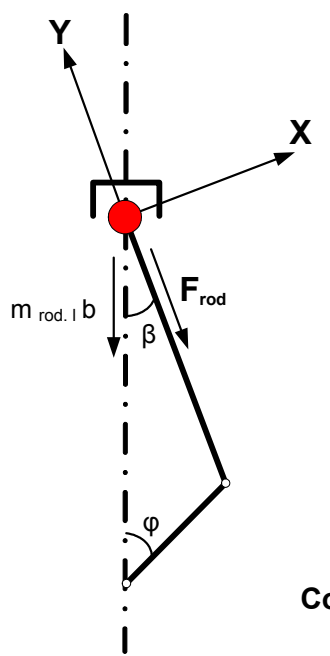

Connecting Rod Small End Bearing

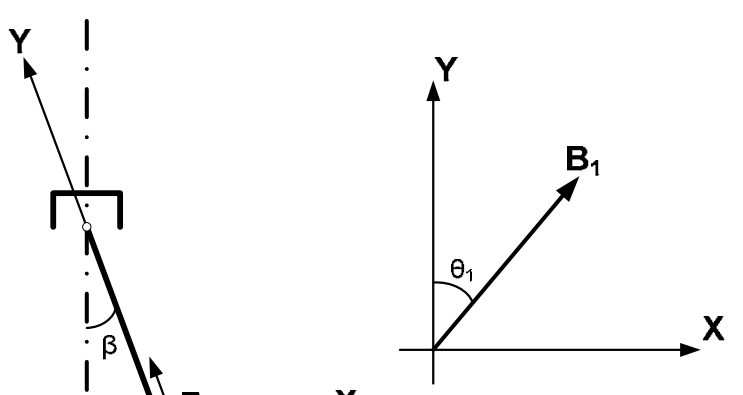

Connecting Rod

Big End Bearing

I

i
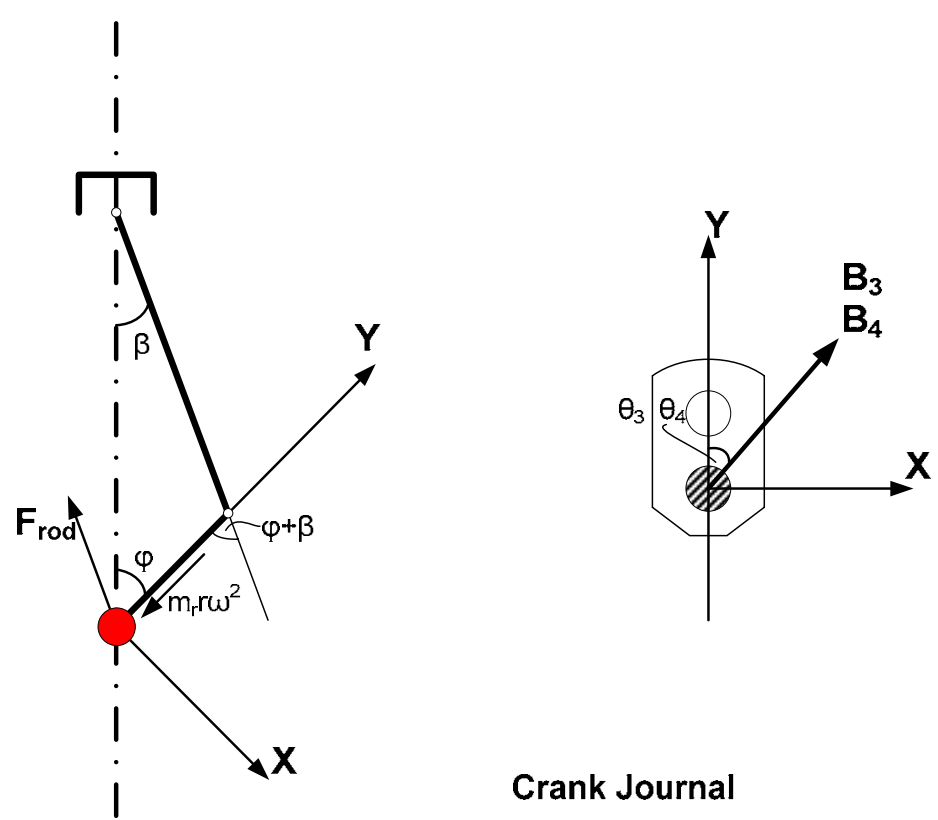

Crank Journal

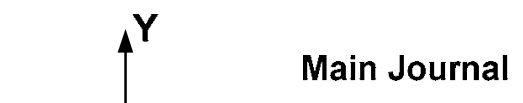

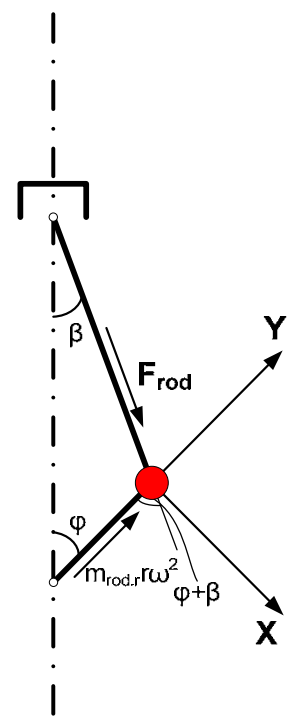

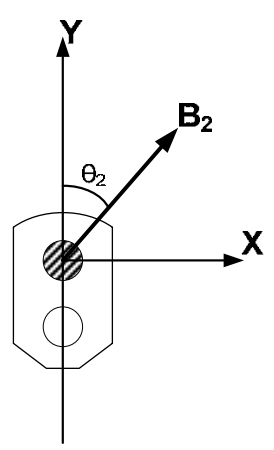

Fig. 3. Force distribution for bearing loadings evaluation 


$$
\begin{gathered}
B_{3 x}=-\frac{F(\varphi)}{\cos \beta} \sin (\varphi+\beta) \\
B_{3 y}=\left[\frac{F(\varphi)}{\cos \beta} \cos (\varphi+\beta)-\left(m_{\text {rod.r }}+m_{\text {crank }}\right) \cdot r \omega^{2}\right]
\end{gathered}
$$

for the crank journal ${ }^{1}$, and

$$
\begin{gathered}
\mathrm{B}_{4 \mathrm{x}}=-\left[\mathrm{F}(\varphi) \tan \beta+\left(\mathrm{m}_{\text {rod.r }}+\mathrm{m}_{\text {crank }}\right) \cdot r \omega^{2} \sin \varphi\right] \\
\mathrm{B}_{4 \mathrm{y}}=\left[-\mathrm{F}(\varphi)+\left(\mathrm{m}_{\text {rod. } \mathrm{r}}+\mathrm{m}_{\text {crank }}\right) \cdot r \omega^{2} \cos \varphi\right]
\end{gathered}
$$

for the main crankshaft bearing.

The corresponding total bearing force is then

$$
\mathrm{B}_{\mathrm{i}}=\sqrt{\mathrm{B}_{\mathrm{ix}}^{2}+\mathrm{B}_{\mathrm{iy}}^{2}}
$$

and the angle $\theta$, shown in Fig. 3 , is given by

$$
\theta_{\mathrm{i}}=\tan ^{-1}\left(\frac{\mathrm{B}_{\mathrm{ix}}}{\mathrm{B}_{\mathrm{iy}}}\right)
$$

with $\mathrm{i}=0 \ldots 4$ according to the bearing studied.

In Eqs (5-9), $\beta$ corresponds to the connecting rod angle (see also Fig. 2), i.e. $\beta=\cos ^{-1}\left[\sqrt{\left(1-\lambda^{2} \sin ^{2} \varphi\right)}\right]$.

The total force acting on the piston is composed of the gas and the inertia force, i.e. $F(\varphi)=F_{g}(\varphi)+F_{1}(\varphi)$, which then propagates into the thrust force $F_{\text {thr }}(\varphi)=F(\varphi) \cdot \tan \beta$ and the force in the direction of the connecting rod $F_{\text {rod }}(\varphi)=F(\varphi) / \cos \beta$. The gas force is determined by $F_{g}(\varphi)=\left(p_{g}(\varphi)-p_{a t m}\right) \cdot A_{\text {pist }}$ while the reciprocating masses (inertia) force by $F_{1}(\varphi)=-m_{1} \cdot b(\varphi)$, with the reciprocating mass $m_{l}=m_{\text {rod.l }}+m_{\text {pist }}$ and $m_{\text {rod.l }}=m_{\text {rod }}-m_{\text {rod.r }}$, i.e. the connecting rod is assumed equivalent to two masses, one reciprocating with the piston assembly and the other rotating with the crank.

\section{FRICTION MODELING}

For the computation of friction torque, at each degree crank angle, the model proposed by Taraza et al. [21] is adopted, which describes the non-steady profile of friction torque during each cycle. In this model the total amount of friction is divided into four parts, i.e. piston rings assembly (including piston rings and piston skirt contribution), loaded bearings, valve train and auxiliaries. A brief description of the model will be given in the next sub-sections. More details can be found in Refs $[21,27,13]$.

\footnotetext{
${ }^{1}$ For each bearing force in Eqs (8) and (9), the contribution from both cylinders that surround this journal is taken into account.
}

An important aspect of friction theory is the mode of lubrication, which as shown in Fig. 4 can be hydrodynamic, mixed or boundary. In hydrodynamic friction the surfaces are separated by a liquid film, minimizing the respective wear. As the pressure increases or the speed decreases, the oil film thins out to the point where its thickness is comparable in size to the surface irregularities. This is the mixed lubrication regime. With further increase in load or decrease in speed, the boundary layer regime is reached, which, for internal combustion engine applications, is experienced around dead centers, at engine start-up and shut-down modes [28].

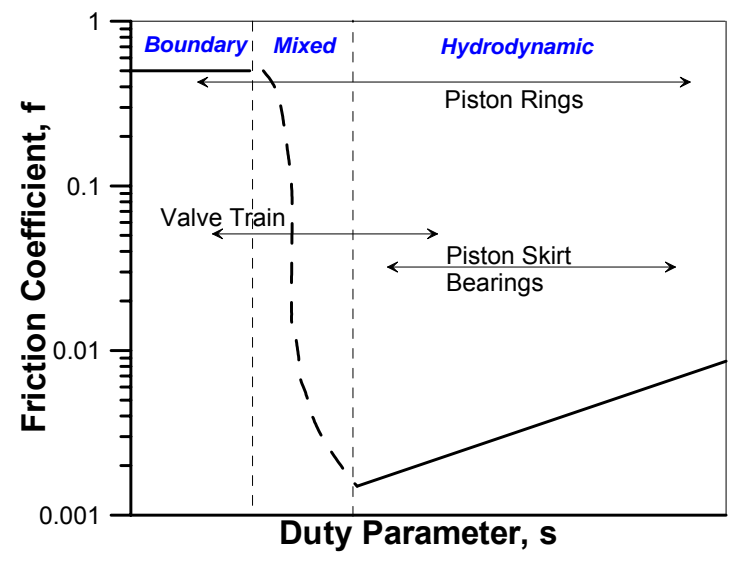

Fig. 4. Stribeck diagram of friction coefficients for various internal combustion engine components

\section{Piston rings assembly}

For most of the piston stroke, lubrication is assumed hydrodynamic, with metal contact occurring near firing TDC. The duty parameter $s$ of the typical Stribeck diagram (see also Fig. 4) is defined by

$$
\mathrm{s}=\frac{\mu_{\text {oil }}\left|\mathrm{u}_{\text {pist }}\right|}{\mathrm{F}_{\text {ring }} / L_{\text {ring }}}
$$

with $L_{\text {ring }}$ the active length of the ring profile, $U_{\text {pist }}$ the instantaneous piston velocity from Eq. (4a), and $F_{\text {ring }}$ the normal force of the ring profile, which is the sum of the ring diametral elastic tension and the instantaneous force from the gas pressure inside the cylinder.

Oil viscosity $\mu_{\mathrm{oil}}$ is approximated by the Vogel equation

$$
\mu_{\text {oil }}=C_{\text {oil }} \cdot e^{\left(\frac{\Theta_{1}}{\Theta_{\text {oil }}+\Theta_{2}}\right)}
$$

where $C_{\text {oil, }} \Theta_{1}$ and $\Theta_{2}$ are constants depending on the oil type [29], and $\Theta_{\text {oil }}$ is the mean, over an engine cycle, oil temperature in ${ }^{\circ} \mathrm{C}$. Increase in oil temperature is generally desirable as it reduces the oil film viscosity, 
thus decreasing the amount of friction; however, some researchers have reported an increase in engine wear [9].

For hydrodynamic lubrication $\left(\mathrm{s}>\mathrm{s}_{\mathrm{cr}}\right)$, the friction coefficient is $[8,9]$

$$
f_{p r}=C \cdot s^{m}
$$

whereas, for the mixed lubrication regime $\left(s<s_{c r}\right)$, it is

$$
f_{p r}=f_{o}\left(1-\frac{s}{s_{c r}}\right)+f_{c r} \frac{s}{s_{c r}}
$$

with $\mathrm{f}_{\mathrm{o}}=0.28, \mathrm{~s}_{\mathrm{cr}}=0.00001$ (for cast iron), and $\mathrm{f}_{\mathrm{cr}}=\mathrm{C} \cdot \mathrm{s}_{\mathrm{cr}}^{\mathrm{m}}$.

The corresponding ring friction force, computed separately for each (compression and oil) ring, is then

$$
\mathrm{F}_{\mathrm{pr}}=\mathrm{f}_{\mathrm{pr}} \mathrm{F}_{\text {ring }}
$$

The oil film thickness between ring and cylinder liner is given by

$$
\mathrm{h}_{\text {oil }} \cong \mathrm{w}_{\text {ring }} \mathrm{s}
$$

with the Stribeck duty parameter 's' given by Eq. (11). An approximation sign is used in Eq. (15) since at the dead centers, where the piston velocity and hence the duty parameter ' $s$ ' are zero, the oil film thickness ' $h_{\text {oil }}$ ' is not zero due to oil squeeze effects.

For the piston skirt similar considerations are made, bearing in mind that lubrication is here always hydrodynamic. The corresponding friction coefficient is $[21,27]$

$$
f_{p s}=C_{p s} \sqrt{\frac{\mu_{o i l}\left|u_{p i s t}\right|}{F_{\text {thr }} / L_{p s}}}
$$

and the respective friction force

$$
F_{p s}=f_{p s} F_{t h r}
$$

where $L_{p s}$ is the length of the piston skirt. Total piston rings assembly friction torque is given by

$$
\mathrm{T}_{\mathrm{pra}}=\mathrm{T}_{\mathrm{pr}}+\mathrm{T}_{\mathrm{ps}}=\left(\mathrm{F}_{\mathrm{pr}}+\mathrm{F}_{\mathrm{ps}}\right) \cdot \mathrm{r} \cdot \frac{\mathrm{u}_{\mathrm{pist}}}{\mathrm{r} \omega}
$$

\section{Loaded bearings}

Friction in bearings is mainly hydrodynamic with the deformation of the bearing housing, due to the applied loading playing an important role. The bearing friction force is computed from the following equation [21]

$$
F_{b}=\frac{2 \pi \mu_{\text {oil }} R_{b}^{2} \omega L_{b}}{c_{b} \sqrt{1-\alpha^{2}}}+\frac{e_{b} \cdot B}{2 R_{b}} \sin \varphi
$$

where $R_{b}$ is the bearing radius, $e_{b}$ the eccentricity, $c_{b}$ the radial clearance, $L_{b}$ the length of the bearing, $a=e_{b} / c_{b}$, and $B$ the bearing loading computed from Eq. (6) or (9). For a constant loaded bearing, friction force will correspond to the short bearing theory, according to which it holds [21]

$$
\frac{B / L_{b}}{R_{b} \omega \mu_{\text {oil }}}\left(\frac{c_{b}}{R_{b}}\right)^{2}\left(\frac{2 R_{b}}{L_{b}}\right)^{2}=\frac{\pi \cdot a}{\left(1-\alpha^{2}\right)^{2}} \sqrt{0.62^{2}+1}
$$

This analysis is carried out twice, once for the connecting rod big end bearing (corresponding loading $\left.B_{1}\right)$, and once for the main crankshaft bearing (corresponding loading $\mathrm{B}_{4}$ ). An iterative method is required in order to solve Eq. (20), which will provide the value of eccentricity ratio a needed in Eq. (19).

The respective bearing friction torque is then

$$
T_{b}=F_{b} R_{b}
$$

\section{$\underline{\text { Valve train }}$}

Valve train friction is governed by friction between cam and tappet, being mainly elasto-hydrodynamic. Valve friction force is given by [21]

$$
\mathrm{F}_{\text {valve }}=0.11 \mathrm{~F}_{\text {cam }}(1-\xi)
$$

for $\xi<1$ (boundary lubrication), while for $\xi>1$ (elastohydrodynamic lubrication) it holds

$$
\mathrm{F}_{\text {valve }}=\frac{2 \mathrm{z} \cdot \mu_{\mathrm{oil}} \cdot \mathrm{L}_{\mathrm{cam}}}{\mathrm{h}_{\mathrm{oil}}}
$$

where $L_{c a m}$ is the length of the cam and $z$ the half width of the Hertzian line contact. Force $F_{\text {cam }}$ between cam and tappet is given by

$$
\mathrm{F}_{\text {cam }}=\left(\mathrm{F}_{\mathrm{o}}+\mathrm{K}_{\mathrm{s}} \frac{\mathrm{L}_{\text {valve }}}{2}\right) \mathrm{A}_{\mathrm{R}}+\mathrm{m}_{\text {cam }} \alpha_{\text {tip }}
$$

with $F_{0}$ the preloading force of the valve spring, $K_{S}$ its stiffness, $L_{\text {valve }}$ the instantaneous valve lift, $A_{R}$ the arm ratio of the rocker arm, $m_{\text {cam }}$ the mass of the cam, and $\alpha_{\text {tip }}$ the acceleration of the tappet at the tip of the cam.

The corresponding friction torque is

$$
\mathrm{T}_{\text {valve }}=\mathrm{F}_{\text {valve }} R_{\text {cam }}
$$




\section{$\underline{\text { Auxiliaries }}$}

For the engine in hand, the auxiliaries consist of the fuel injection pump, the water pump and the oil pump; other engine applications may include the fan of the cooling system, the air-conditioning pump etc. Particularly as regards the injection pump, the corresponding friction torque consists of two terms, one dealing with the operation of the low-pressure fuel pump and the other accounting for the spike during injection. It holds

$$
\mathrm{T}_{\text {aux }}(\varphi)=\mathrm{T}_{\text {f.pump }}(\varphi)+\mathrm{T}_{\text {oil.pump }}(\varphi)+\mathrm{T}_{\text {w.pump }}(\varphi)
$$

\section{$\underline{\text { Total friction torque }}$}

Total friction toque at each degree crank angle is the sum of the above friction terms (Eqs (18), (21), (24) and (25)), i.e.

$$
T_{\text {fr }}(\varphi)=T_{\text {pra }}(\varphi)+T_{b}(\varphi)+\frac{1}{2} T_{\text {valve }}(\varphi)+T_{\text {aux }}(\varphi)
$$

Despite the great number of equations needed for application of this detailed friction model, the respective increase in the computational time of the simulation code is minimal since, apart from the iterative method of Eq. (20), all other equations involved are simple algebraic ones; the only obstacle is really the need to find a multitude of (geometric) data of the engine subsystems.

\section{FUEL PUMP OPERATION}

Instead of using steady-state fuel pump curves during transients, a fuel injection model, experimentally validated at steady-state conditions, is applied. Thus, simulation of the fuel pump-injector lift mechanism is accomplished, taking into account the delivery valve and injector needle motion [30]. The unsteady gas flow equations are solved using the method of characteristics, providing the dynamic injection timing as well as the duration and rate of injection for each cylinder at each transient cycle. The obvious advantage here is that the transient operation of the fuel pump is also taken into account. This is mainly accomplished through the fuel pump residual pressure value, which is built up together with the other variables during the transient event.

\section{MULTI-CYLINDER ENGINE MODELING}

At steady-state operation the performance of each cylinder is essentially the same, owing to the quasisteady position of the governor clutch resulting in the same amount of fuel being injected per cycle, and the quasi-steady turbocharger compressor operating point. Under transient operation, however, each cylinder experiences different fuelings and air mass flow-rates during the same engine cycle. This happens due to the combined effect of: a) the continuous movement of the fuel pump rack that is initiated by a load or speed change, and b) the continuous movement of the turbocharger compressor operating point. As regards speed changes, only the first cycles are practically affected. However, when load changes are investigated, significant variations can be experienced throughout the whole transient cycle. The usual approach, here, is the solution of the governing equations for one cylinder and the subsequent use of suitable phasing images of this cylinder's behavior. This approach is widely popular for limiting the computational time [7]. Unlike this, the present research group has developed a true multicylinder engine model. Here, all the governing differential and algebraic equations are solved individually for every one cylinder of the six-cylinder engine under study, according to the current values of the fuel pump rack position and turbocharger compressor flow. This results to (significant) differentiations in both fueling and air mass flow-rates for each cylinder during the same cycle of a transient event.

\section{CRANKSHAFT EQUILIBRIUM}

Engine speed exhibits a non-steady profile during an engine cycle, even at steady-state engine operation. The updated values of crankshaft rotational speed and angular acceleration during transients are derived from the conservation of angular momentum in the total system (engine and load). For the general case where the stiffness and damping of the crankshaft is taken into account, the following two equations hold [31,7], with reference also to Fig. 5,

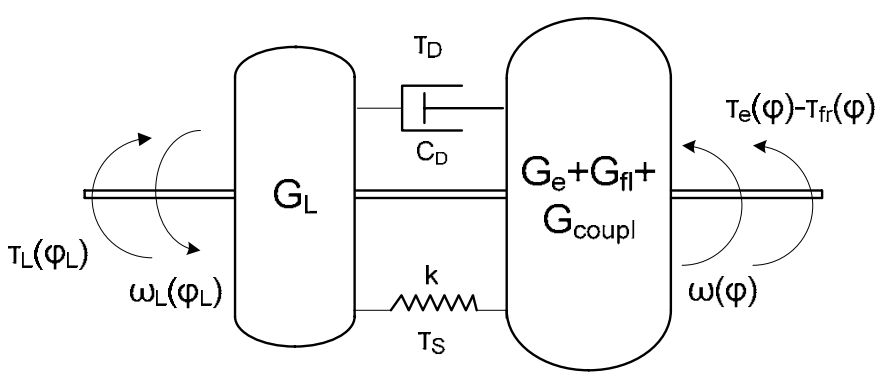

Fig. 5. Schematic arrangement of engine-load dynamic system for crankshaft angular momentum equilibrium analysis

$$
\begin{aligned}
T_{e}(\varphi)-T_{f r}(\varphi)-T_{S}-T_{D} & =G \frac{d \omega}{d t}+\frac{1}{2} \frac{d G}{d \varphi} \omega^{2} \\
T_{S}+T_{D}-T_{L}\left(\varphi_{L}\right) & =G_{L} \frac{d \omega_{L}}{d t}
\end{aligned}
$$

Here, $G$ is the engine moment of inertia (comprising all rotating and reciprocating parts $G_{e}$, the flywheel $G_{f f}$, and the elastic coupling ${ }^{2} G_{\text {coupl }}$ ) and $G_{L}$ is the load mass

\footnotetext{
${ }^{2}$ A torsional vibration analysis carried out on the engine, revealed that, for the rated speed of $1500 \mathrm{rpm}$, the engine operates close to resonance with the $3^{\text {rd }}$ harmonic order of the first natural mode. Hence, an elastic coupling is applied.
} 
moment of inertia. In the rhs of Eq. (27a), the first term represents the rotating masses inertia torque and the second term the reciprocating masses contribution. Also, $\omega_{\mathrm{L}}=\frac{d \varphi_{\mathrm{L}}}{\mathrm{dt}}$ is the load angular velocity, while the torsional deformation of the crankshaft, corresponding to the instantaneous difference between engine and load torque, is $\varphi-\varphi_{L}$. Further, $T_{e}$ denotes the engine indicated torque that includes gas, inertia and (the negligible) gravitational forces contribution. Engine torque is mostly dependent on correct combustion modeling; it is given explicitly by [32]

$$
\begin{gathered}
T_{e}(\varphi)=T_{g}(\varphi)+T_{\text {in }}(\varphi)+T_{g r}(\varphi)= \\
{\left[\left(p_{g}(\varphi) \cdot A_{\text {pist }} \cdot \frac{u_{\text {pist }}(\varphi)}{r \omega}\right)+F_{\text {Tin }}(\varphi)+\left(m_{l} g \frac{u_{\text {pist }}(\varphi)}{r \omega}+m_{r} g \sin \varphi\right)\right] r}
\end{gathered}
$$

In the above relation, $p_{g}(\varphi)$ is the instantaneous cylinder pressure, $m_{l}=m_{\text {pist }}+m_{\text {rod.l }}$ is the reciprocating mass, and $m_{r}=m_{\text {crank }}+m_{\text {rod. } r}$ is the rotating mass of each slider-crank mechanism. Also, $F_{T i n}$ is the torsional (tangential) inertia force (acting perpendicularly to the crank axis), the analysis of which is given in Appendix A, $\mathrm{T}_{\mathrm{fr}}$ is the total friction torque computed from Eq. (26), $\mathrm{T}_{S}=\mathrm{T}_{S}(\varphi)=\mathrm{k}\left(\varphi-\varphi_{\mathrm{L}}\right)$ is the stiffness torque, with $\mathrm{k}$ the stiffness coefficient (assumed constant) ${ }^{3}$, and $T_{D}=T_{D}(\varphi)=C_{D}\left(\omega-\omega_{L}\right)$ is the damping torque, with $C_{D}$ the damping coefficient. Finally, $T_{L}$ is the load torque, which is approximated by the following relation,

$$
\mathrm{T}_{\mathrm{L}}\left(\varphi_{\mathrm{L}}\right)=\mathrm{C}_{1}+\mathrm{C}_{2} \omega_{\mathrm{L}}^{\mathrm{C}_{3}}
$$

For a linear load-type (i.e. electric brake, generator) $\mathrm{C}_{3}=1$, for a quadratic load-type (i.e. hydraulic brake, fixed pitch propeller, vehicle aerodynamic resistance) $\mathrm{C}_{3}=2$, with $\mathrm{C}_{1}$ being the speed-independent load term (e.g. road slope).

Equations (27) can be further expanded if we consider the torsional deformations between each couple of consecutive engine cylinders, the flywheel and the load. Then, a set of 7 differential equations has to be solved for the angular momentum equilibrium of the particular six-cylinder engine.

\section{CONNECTING ROD MODEL}

The connecting rod is usually modeled as equivalent to two-lumped masses concentrated at its ends, i.e. one

\footnotetext{
${ }^{3}$ It is reminded here that if the crankshaft is assumed rigid enough (as is the usual case in transient simulations), then $\varphi \equiv \varphi_{\mathrm{L}}$ and Eqs (27) are replaced by $T_{e}(\varphi)-T_{\text {fr }}(\varphi)-T_{L}(\varphi)=G_{\text {tot }} \frac{d \omega}{d t}$, where $G_{\text {tot }}$ represents the total mass moment of inertia of the engine-load configuration reduced to the crankshaft axis.
}

reciprocating with the piston assembly and the other rotating with the crank pin. This approach was followed in a previous section for calculating the bearings loading, and it is widely adopted for simplicity. However, it induces errors in the slider-crank mechanism dynamics by miscalculating the actual rod's moment of inertia and the various forces of the kinematic mechanism. For a more accurate computation of engine torque, we have developed a detailed model of the connecting rod based on rigid body dynamics. Here, we analyze the complex, elliptical movement of the rod's center of gravity that is produced by its reciprocating and rotating motion. A system of $3 X 3$ equations provides the respective inertia force $F_{\text {Tin }}$ 'acting' perpendicularly to the crank axis (see Fig. 2) that is needed in Eq. (28). Details about this analysis are given in Appendix A. Figure 6 demonstrates the difference in the inertia force results, obtained by using the rigid body and the lumped mass models for an early cycle of a load increase transient. As can be observed, the simplified model generally overestimates the inertia force, particularly at the crank angles where the local maxima or minima occur. A sensitivity analysis carried out using both approaches showed that the detailed connecting rod model resulted in only modest differentiations (of the order of 1\%) in the engine speed response predictions, compared to the lumped mass approach.

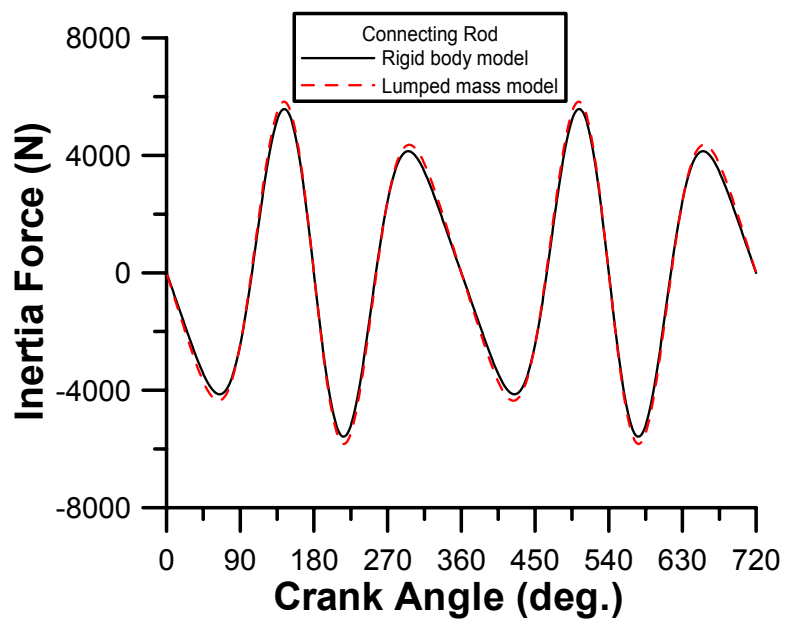

Fig. 6. Inertia force development during an engine cycle: Comparison between connecting rod rigid body and lumped mass models

\section{EXPERIMENTAL VALIDATION}

The experimental investigation was carried out on a heavy-duty six-cylinder, turbocharged and aftercooled, medium-high speed diesel engine. The basic data for the engine are given in Table 1.

Before exercising the transient model, an extended series of steady-state runs was conducted in order, on the one hand, to assess the model's predictive capabilities and, on the other hand, to calibrate successfully the individual sub-models described in the 
previous sections. By so doing, the constants for the combustion, heat transfer, friction, etc, sub-models were made possible to be estimated. Furthermore, the measurement of the recorded pressure diagrams area made possible to estimate the total fmep of the engine that is needed in the calibration of the friction models.

Table 1. Engine Data

\begin{tabular}{|cc|}
\hline Engine Type & $\begin{array}{c}\text { 6-cylinder, 4-stroke, } \\
\text { turbocharged and } \\
\text { aftercooled, heavy-duty } \\
\text { diesel engine }\end{array}$ \\
\hline Speed Range & $1000 \div 1500 \mathrm{rpm}$ \\
\hline Bore / Stroke & $140 \mathrm{~mm} / 180 \mathrm{~mm}$ \\
\hline Maximum Power & $236 \mathrm{~kW} \mathrm{@} 1500 \mathrm{rpm}$ \\
\hline Maximum Torque & $1520 \mathrm{Nm} \mathrm{@} 1250 \mathrm{rpm}$ \\
\hline $\begin{array}{c}\text { Total Moment of } \\
\text { Inertia (engine and } \\
\text { load) }\end{array}$ & $15.60 \mathrm{~kg} \mathrm{~m}{ }^{2}$ \\
\hline
\end{tabular}

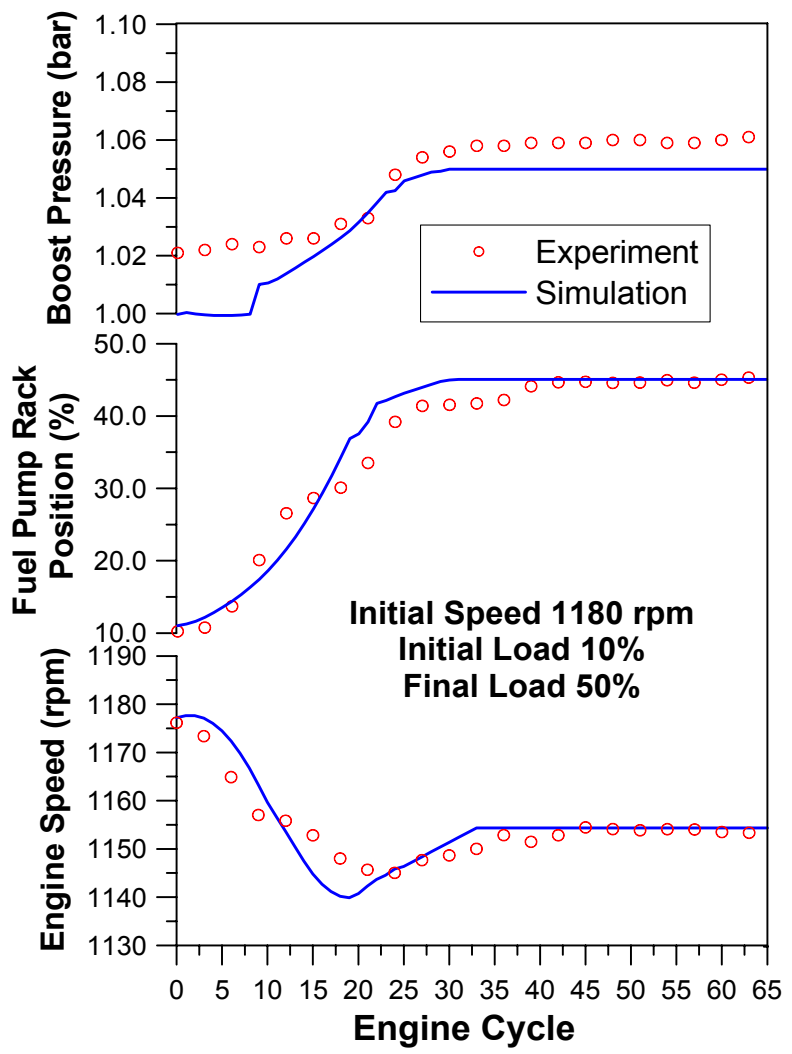

Fig. 7. Experimental and predicted engine transient response to an increase in load

The investigation of transient operation was the next task. Since the particular engine is one with a relatively small speed range, mainly load changes (increases) with constant governor setting were examined [6]. A typical example of a conducted transient experiment is given in Fig. 7. Here, the initial load was $10 \%$ of the full engine load at $1180 \mathrm{rpm}$. The final applied load was almost $50 \%$ of the full engine load. The non-linear character of the load application, which could not be accounted for in the simulation, is responsible for the differences observed in boost pressure and engine speed response. The particular hydraulic brake has a very high mass moment of inertia, of the order of $5.375 \mathrm{~kg} \mathrm{~m}^{2}$, resulting in long, abrupt and non-linear actual load-change profiles. Nonetheless, the matching between experimental and predicted transient responses seems satisfactory for all engine and turbocharger variables measured (engine speed, fuel pump rack position and boost pressure), and is believed to form a sound basis for the theoretical investigation of the various dynamic issues that arise during transient diesel engine operation.

\section{RESULTS AND DISCUSSION}

\section{A) CRANKSHAFT DEFORMATION}

Figure 8 illustrates the development of crankshaft torsional (angular) deformation, i.e. term $\left(\varphi-\varphi_{\llcorner}\right)$from Eqs (27), during steady-state engine operation. A 'singlecylinder version' of the current engine was initially chosen for this analysis, in order for the results to be readily tangible by direct comparison with the in-cycle pressure and engine torque build-up.

During compression $\left(0-180^{\circ} \mathrm{CA}\right)$, a deficit of gas torque exists that leads to engine speed decrease and to the 'negative' crankshaft deformation shown in Fig. 8. After the start of combustion, there is a surplus of torque, as now the engine enters the power producing phase of operation. Consequently, 'positive' deformation is established, while the instantaneous engine speed increases. This lasts for the whole expansion stroke. The considerably higher amount of engine torque produced during expansion leads to the greater local peak in crankshaft deformation, i.e. 0.16 deg occurring at about $55^{\circ} \mathrm{CA}$ after firing TDC, compared to the local minimum of -0.03 deg at $180^{\circ} \mathrm{CA}$ ( $70 \%$ load operation).

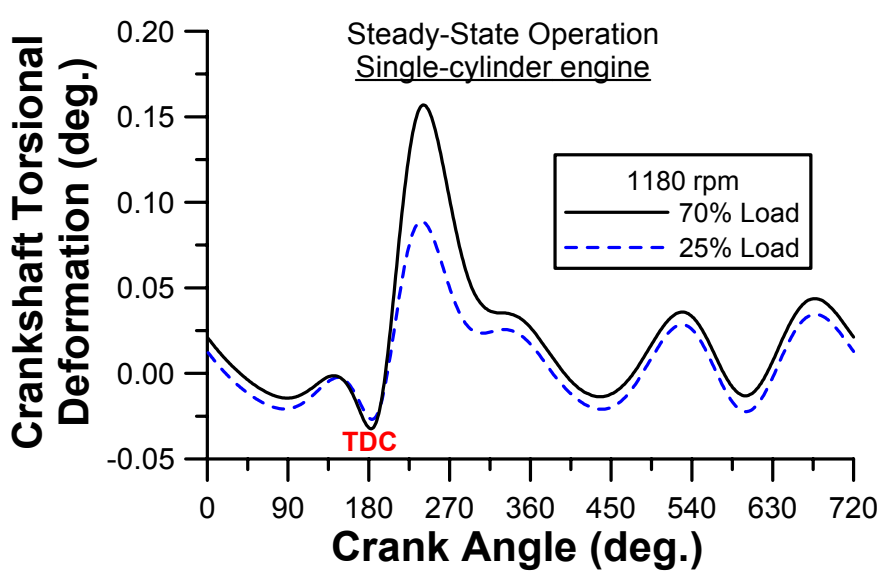

Fig. 8. Development of crankshaft torsional deformation during steadystate engine operation 
The main mechanism behind the crankshaft torsional deformation profile over an engine cycle is clearly the gas torque because of its direct impact on total engine torque. Closer examination of Fig. 8 reveals that inertia torque influence is also observed, mainly during the open part of the cycle where the cylinder pressure is low, as well as during the second half of compression. For the present engine the inertia contribution is rather small due to the low engine speed (recall that inertia forces depend on the engine speed squared).

The torsional deformation for the $25 \%$ load is also depicted in Fig. 8 for comparison purposes. Here, lower maxima of crankshaft deformation are overall observed. This was intuitively expected, because of the lower values of fueling and consequently engine gas torque produced during this cycle (inertia forces retain the same values as in the $70 \%$ load case since the engine speed is the same). Likewise, smaller deformations are to be expected for naturally aspirated diesel or for spark ignition engine operation, where the cylinder pressures are much lower. In the latter cases, a greater influence of inertia torque is also expected, particularly for small Otto (car) engines operating at high rotational speeds.

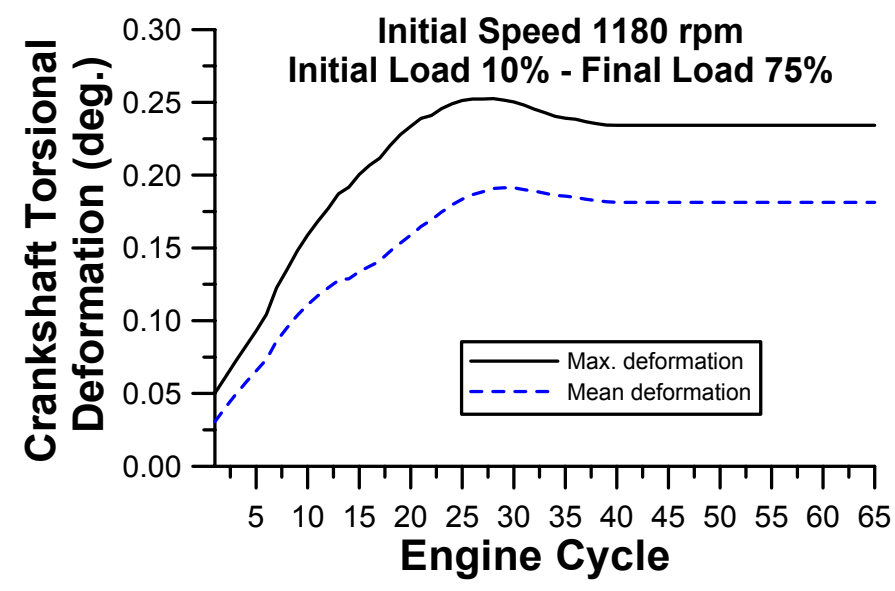

Fig. 9. Development of maximum and mean, over an engine cycle, crankshaft angular deformation during a load increase transient event

Figure 9 depicts the development of the maximum and the mean, over each engine cycle, deformation for a typical load increase transient of the six-cylinder engine under study, commencing from an engine speed of 1180 $\mathrm{rpm}$. Initially, the deformation is negligible due to the low engine load (cf. Fig. 8). As the governor responds to the drop in engine speed caused by the abrupt load increase, the fueling increases too leading to higher gas pressures and torques throughout the cycle. This results in greater maximum and mean, over the engine cycle, deformations. It is important to notice that the instantaneous maximum deformation is considerably higher (up to $50 \%$ for the cases examined in this work) than the respective mean value in the same cycle; this justifies the analysis per degree crank angle, in order to be able to estimate the respective 'true' maximum (instantaneous) stress on the crankshaft.

From the analysis it has been revealed that, in principle, the main parameters affecting the profile and values of crankshaft angular deformation during transients are the applied engine load and the crankshaft stiffness, as it is demonstrated in Fig. 10. A higher applied load leads in higher fueling rates and, thus, cylinder pressures/gas torques. Consequently, after the start of combustion the surplus of net torque is now much higher, resulting in greater peaks of crankshaft deformation (cf. the two load curves in Fig. 8 for steady-state engine operation).

The more rigid the crankshaft (greater values of ' $k$ '), the smaller the torsional deformation observed throughout the whole event. An increase of the order of $160 \%$ in the deformation peak is observed when comparing the results between the double and the half stiffness coefficient. Low stiffness (e.g. due to greater physical length of the crankshaft) acts, practically, in the same way as the low moment of inertia, i.e. it allows higher acceleration rates throughout the cycle, thus lowering the engine non-uniformity of rotation.

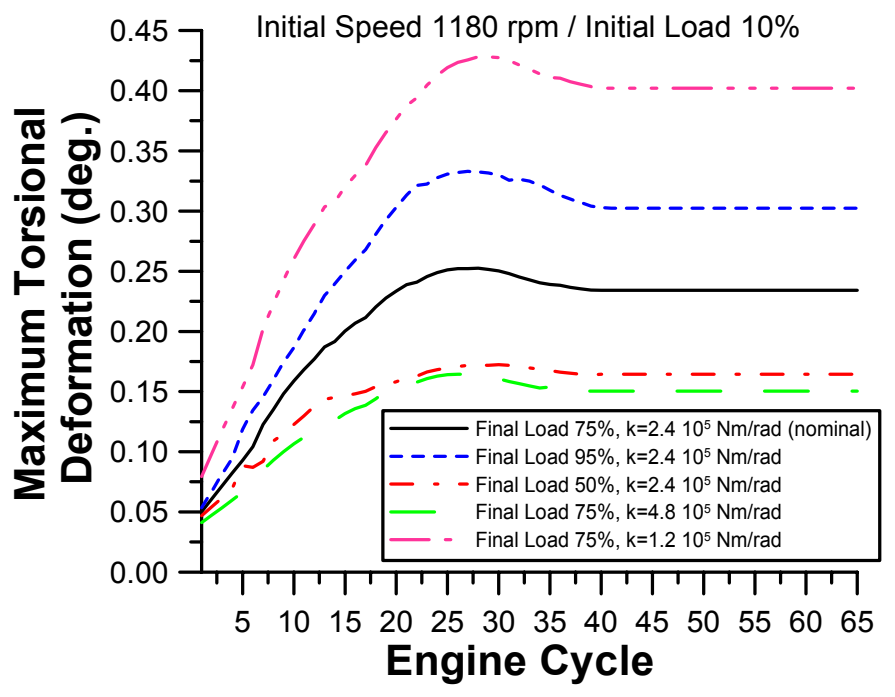

Fig. 10. Effect of applied load and crankshaft stiffness on the maximum, over an engine cycle, torsional deformation during a load increase transient

On the other hand, sensitivity analysis showed that the detailed formulation of the crankshaft angular momentum (Eqs (27)) does not diversify the overall engine (speed) and turbocharger response predictions. Hence, its incorporation in a transient simulation code is necessary only if the study of torsional deformation is the object of research, as it is actually the case in this work. 


\section{B) DEVELOPMENT OF BEARINGS LOADING}

Figure 11 illustrates the development of maximum bearing loadings (Eq. (10a)) during the nominal transient load increase of $10-75 \%$. The response of piston force $\left(=p_{g}(\varphi)^{*} A_{\text {pist }}\right)$, engine speed and fueling are also depicted in the same figure for comparison.

The main findings are:

- The maximum values, over each engine cycle, of all bearing loadings develop during a transient event, in a way that closely follows the fueling and the peak cylinder pressure profile,

- The turbocharger lag effect is obvious during the first 10 cycles of the transient event,

- As expected, the connecting rod's big end bearing loading equals the crank pin's one, whereas the crank journal's loading equals the main crankshaft bearing's loading,

- The loading gradually decreases as we move 'downwards' the kinematics mechanism, i.e. from the piston towards the crankshaft, as the initial gas force is 'propagated',

- The effect of gas pressure is dominant, and this is better illustrated in the $10-95 \%$ load increase case; for the latter, more cycles were needed until the achievement of final convergence,

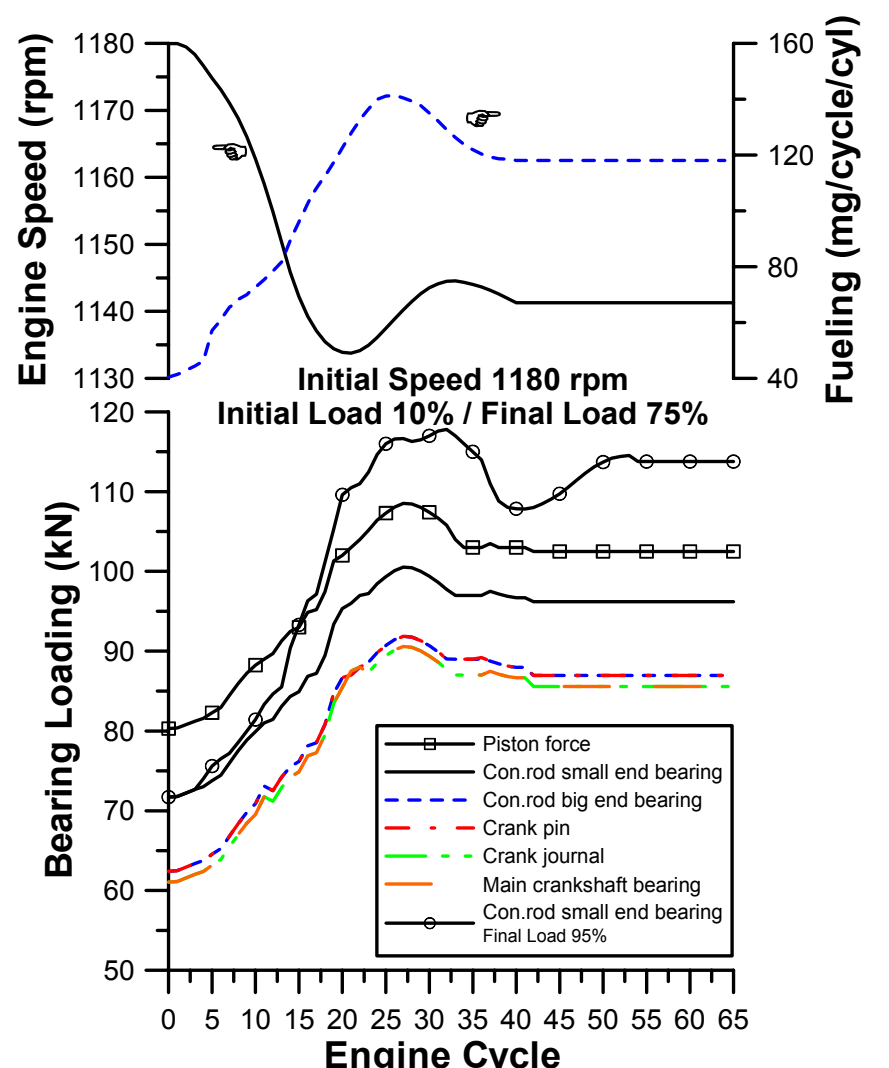

Fig. 11. Maximum bearing loading vs. engine cycle for the $10-75 \%$ load increase
- The contribution of the inertia forces is minimal (as regards the maximum values only - see comments for Fig.12 below regarding in-cycle values), primarily due to the low engine rotational speed (cf. the $\omega^{2}$ term in Eqs. (5)-(9)),

- The crank angle where the maximum loading is observed ranges for all bearings and for all transient cycles between $181-184^{\circ}$ (i.e. $1-4^{\circ} \mathrm{CA}$ after firing TDC, as it is also the case with the peak cylinder pressure), and

- As regards the loading rate, the maximum increase is observed between cycles 10-30 where the main part of the increase in fueling occurs; it is of the order of $16 \mathrm{kN} / \mathrm{s}$ for the $10-75 \%$ load increase.
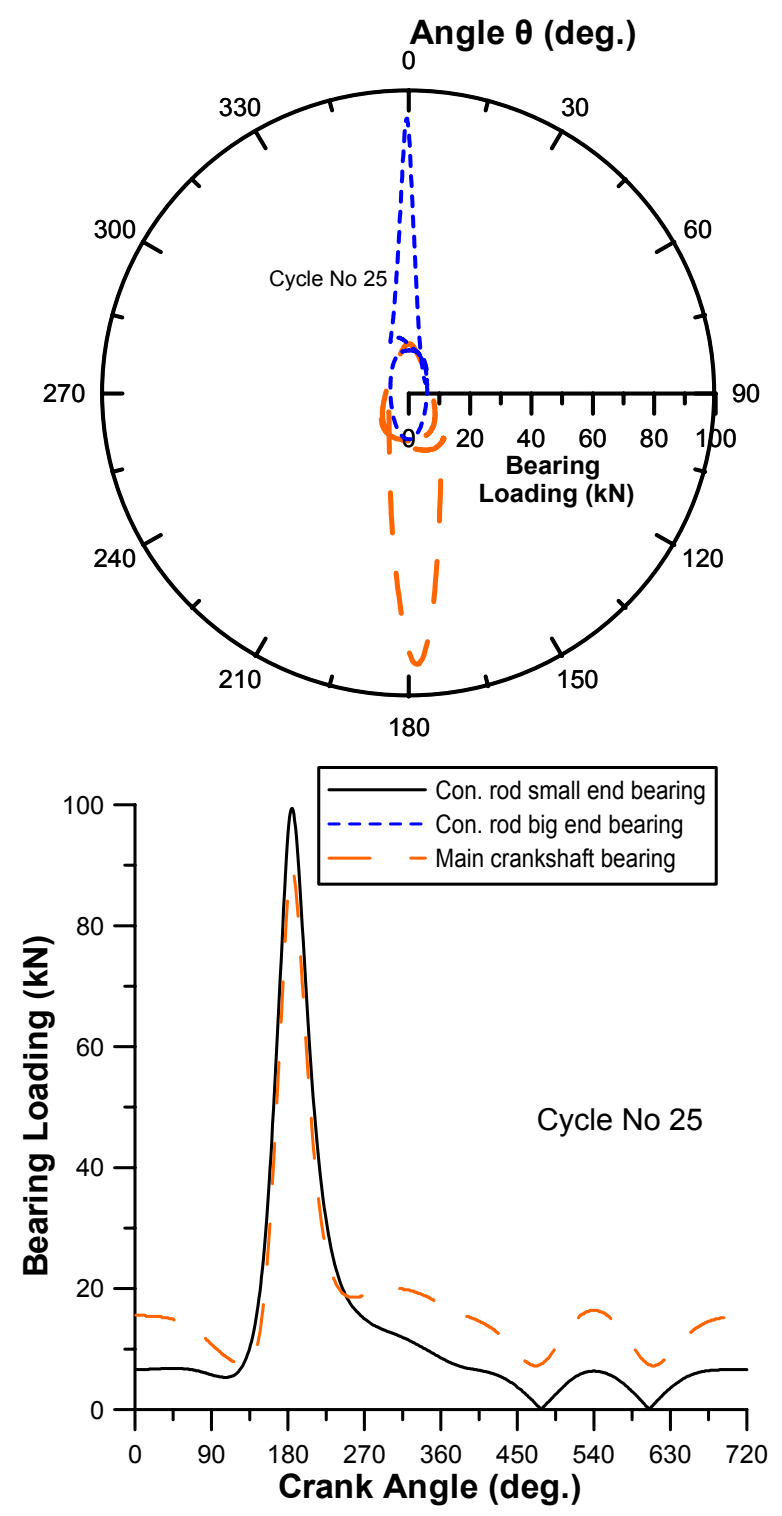

Fig. 12. Development of connecting rod and main crankshaft bearing loadings during an intermediate cycle of the $10-75 \%$ load increase

Figure 12 focuses on an intermediate cycle of the transient event (cycle No 25 where the maximum fueling occurs), illustrating the in-cycle build-up of the 
connecting rod and main crankshaft bearing loadings. The contribution of gas force is evident during the compression and expansion strokes; however, it is the inertia forces that define the loading profile during most of the open part of the cycle, where the cylinder pressure assumes lower values. In the upper diagram of Fig. 12 the above data are illustrated on a polar diagram, which is a more common way of depiction in terms of this kind of analysis.

Figure 13 depicts the development of bearing eccentricity $e_{b}$ during the $10-75 \%$ load increase. This is computed from the iterative procedure of Eq. (20) for the two journals needed in the upcoming friction analysis, i.e. connecting rod big end bearing and main crankshaft bearing.

The profile of the eccentricity follows closely the fueling or respective forces development of Fig. 11. Increased fueling during the transient event produces increased gas pressure forces, thus squeezing the bearings and increasing the respective eccentricity; the overall values, however, differentiate only modestly during the transient event. Although the connecting rod bearing loading is higher, the respective eccentricity is lower than the main crankshaft bearing's one. This is attributed to the greater length of the connecting rod big end bearing (see data in Table 2).

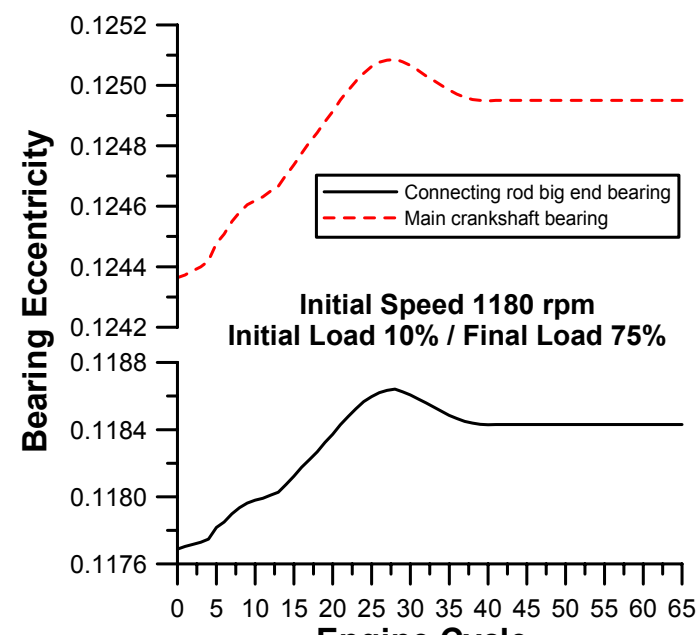

Engine Cycle

Fig. 13. Development of bearing eccentricity during the $10-75 \%$ load increase

\section{C) FRICTION DEVELOPMENT}

Figure 14 illustrates the development of piston ring assembly friction forces, during an engine cycle, for the engine under study. The main data of the engine needed for application of friction equations are provided in Appendix B. The profiles of upper piston ring and piston skirt friction forces, over an engine cycle, are in accordance with the experimental results provided by previous researchers $[9,27,28,33]$ (note that negative values denote piston movement towards the BDC). Shift from hydrodynamic to mixed lubrication occurs around firing TDC, where the oil film temporarily breaks down. This causes a sudden, considerable increase in the friction coefficient $f_{p r}$ that affects also the oil film thickness.

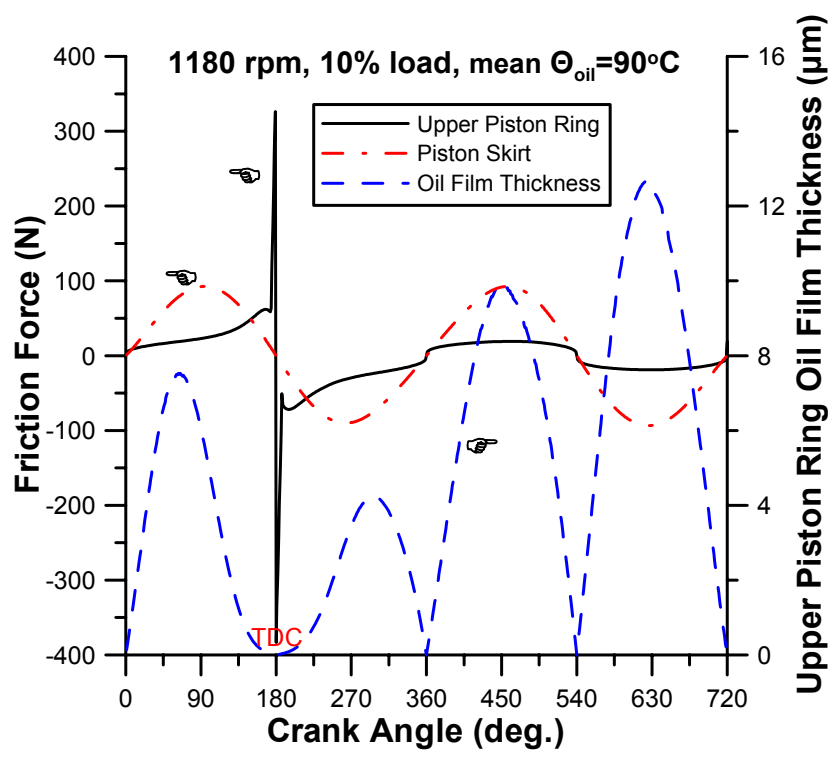

Fig. 14. Variation of piston ring pack friction force and oil film thickness during an early cycle of the $10-75 \%$ transient event

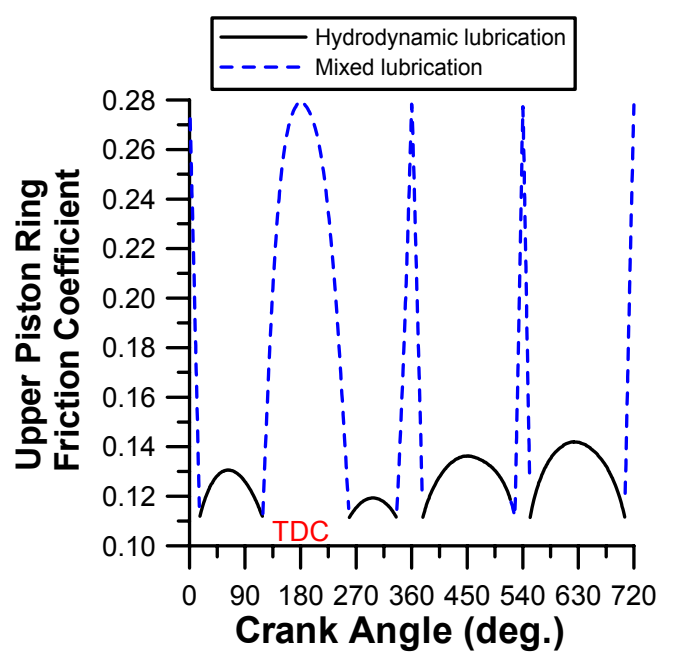

Fig. 15. Development of upper piston ring friction coefficient during an early cycle of the $10-75 \%$ transient event

The latter are further analyzed in Fig. 15, which depicts the development of the instantaneous upper piston ring friction coefficient for the same engine cycle. The effect of the cyclic nature of instantaneous piston velocity $u_{\text {pist }}$ (Eq. (4a)), affecting the Stribeck parameter ' $s$ ', is obvious in this figure. The period of mixed lubrication 
lasts for more degrees CA around firing TDC than around the other three dead centers in the cycle. This is due to the increased $F_{\text {ring }}$ values, because of increased gas pressures during the closed part of the cycle. Closer examination of the curves in Fig. 15 shows that the friction coefficient development (profile and absolute values) remains practically unaltered for each cycle of the transient event (only the duration of mixed lubrication around firing TDC may increase slightly with increased loading/fueling); the maximum value of friction coefficient is determined by the condition of cast iron boundary lubrication $\left(f_{0}\right)$. Thus, the values of the corresponding mean or maximum -over an engine cycle- piston rings friction force or torque during the transient event will be determined solely by the mean or maximum gas pressures, respectively, as will be depicted in Fig. 18 later in this section.

On the other hand, piston skirt friction development in Fig. 14 follows closely the instantaneous piston speed $\mathrm{u}_{\text {pist }}$, as it has already been experimentally established $[8,9,27]$, and it is dictated by Eq. (16). Piston pin, and crank offset have been identified as factors that may distort the near sinusoid variation of piston skirt friction $[27,34]$. Recall that piston skirt lubrication is always maintained in the hydrodynamic region; hence, friction force is always of smaller magnitude compared to the (total) piston rings contribution.

The prediction of oil film thickness variation from Eq. (15) is provided in Fig. 14 too. Metal contact between rings and cylinder liner at firing TDC leads to boundary lubrication, as it was depicted in Fig. 15. Near dead centers, the piston speed approaches zero and hence oil film thickness becomes minimal (cf. comments for Fig. 19 , later in this section, concerning interdependence between oil film thickness and engine speed). Recall that, according to Eq. (15), oil film thickness near dead centers is not zero, since it is determined by oil squeeze effects. However, in order to account for the effect of transverse squeeze action and, hence, accurately predict oil film thickness, solution of the respective twodimensional transient Reynolds equations would be needed [35]. Owing to the considerable decrease of gas pressures during the exhaust and inlet strokes, oil film thickness assumes much higher values after exhaust valve opening. On the other hand, its values are considerably lower during the expansion stroke where the gas pressures are high.

In Fig. 16, a sensitivity analysis is performed in order to assess the importance of incorporating detailed friction modeling for more accurate transient response predictions. Here, we focus on the nominal load increase case of $10-75 \%$, illustrating the engine transient response based on either detailed friction modeling or use of mean fmep equations. For the calculation of fmep, the relation proposed by Chen and Flynn [36] is applied, i.e.

$$
\text { fmep }=\alpha+\beta p_{\max }+\gamma \bar{u}_{\text {pist }}
$$

where $p_{\max }$ is the peak cylinder pressure calculated at the previous engine cycle, $\bar{u}_{\text {pist }}$ is the corresponding mean piston speed, and $\alpha, \beta, y$ are constants derived after calibration against experimental data at steadystate conditions. Consequently, friction torque is given by

$$
T_{f r}^{f m e p}(\varphi)=\bar{T}_{f r}=\left(\text { fmep } \cdot 10^{5}\right) A_{\text {pist }} r / 2 \pi
$$

This friction torque remains constant at each degree crank angle during a cycle, with its values differentiating only from engine cycle to cycle. The important part here is the $\gamma \bar{u}_{\text {pist }}$ factor in Eq. (30), indicating the dominant effect of engine speed on friction torque.

The two speed curves in Fig. 16 almost coincide until cycle 15. This happens because the main change in fueling occurs from cycle 15 onwards, a fact leading to differentiations in gas pressure and consequently in the profile of friction torque and thus engine speed. The mean fmep curve results differ by $5 \%$ as regards both maximum and final engine speed droop from the analytical ones. For higher load changes, e.g. 10-95\%, greater differences are observed of the order of $8 \%$ [13]. Similar results hold for the boost pressure, which is also depicted in Fig. 16, as well as for the other engine and turbocharger variables.

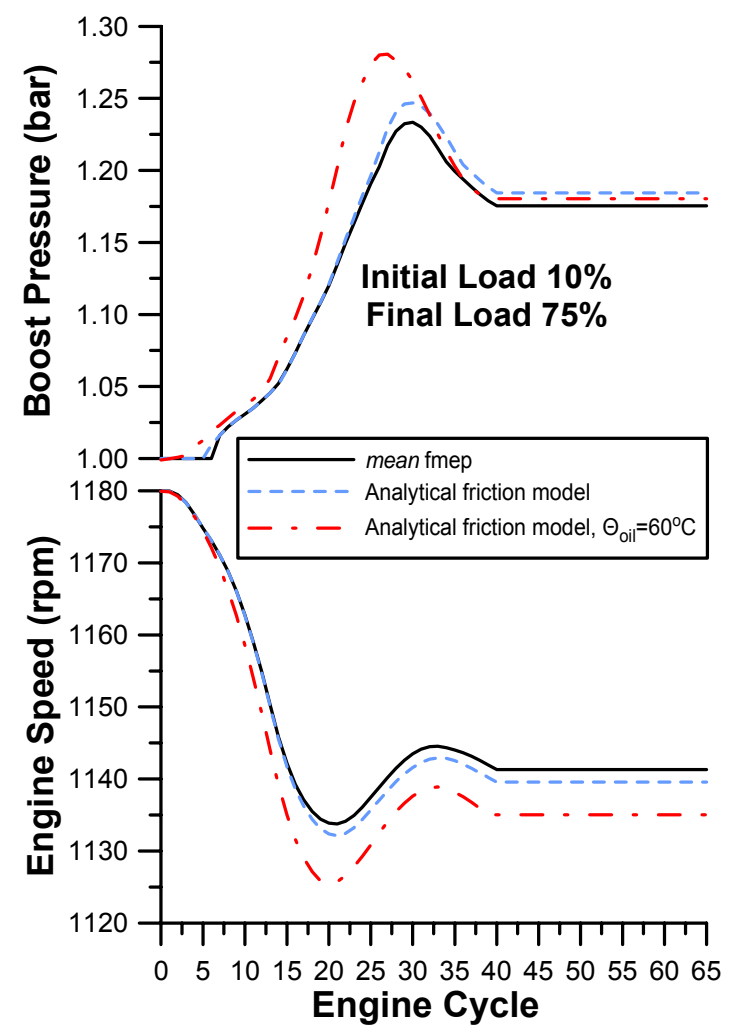

Fig. 16. Comparison of response to an increase in load between mean fmep and analytical friction modeling (10-75\% load increase) 
In the same figure, the case with oil temperature at $60^{\circ} \mathrm{C}$ is also depicted only for the detailed model, since the constant fmep relation does not take into account the effect of such operational parameters. The main mechanism behind the lower oil temperature results is the increased viscosity (Eq. (12)). This produces larger values of the duty parameter ' $s$ ' (Eq. (11)) and hence friction coefficient (Eq. (13a)), and consequently increased piston rings assembly friction that leads to increased total friction torque and thus greater engine speed drops.

It should be noted here that the particular engine-load configuration has a high total mass moment of inertia, of the order of $15.60 \mathrm{kgm}^{2}$, which, when combined with the very small speed range of the engine $(1000 \div 1500 \mathrm{rpm})$, produces slow governor clutch and thus fuel pump rack responses. These in turn lead to relatively slow changes in fueling.

Figure 17 focuses on the development of the reduced 'fmep' term from the Taraza et al. [21] model, which is identified as follows

$$
\text { 'fmep' }{ }_{\text {Taraza }}=\frac{2 \pi \int_{0}^{720} T_{f r}(\varphi) \cdot d \varphi}{A_{\text {pist }} r}
$$

with the term $T_{f r}(\varphi)$ computed from Eq. (26). This fmep response arises from the combined effect of pressures (through fuel pump rack position response) and engine speed development. Bmep development for cylinder No. 1 is also provided on this figure for comparison.

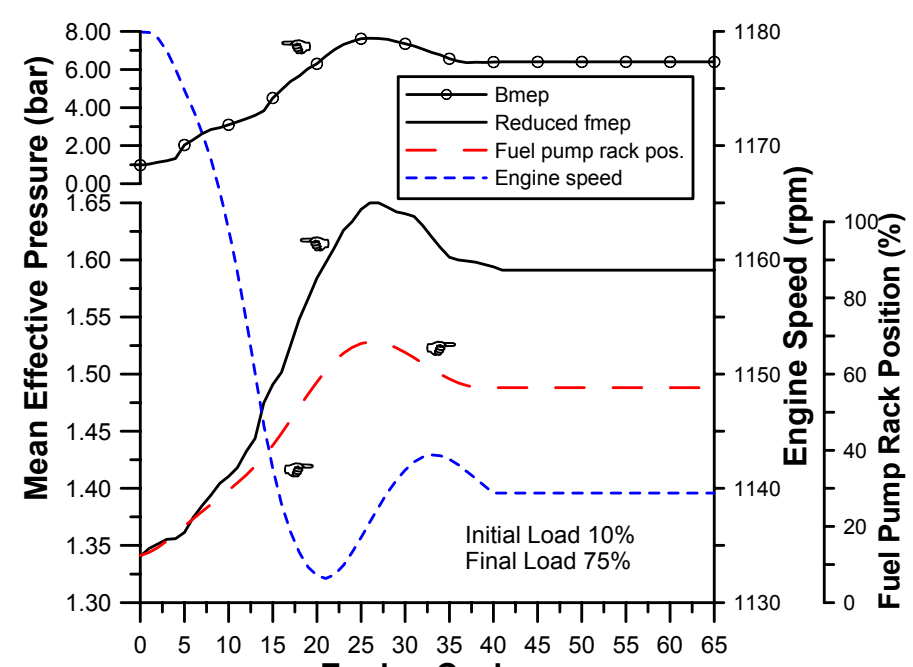
Engine Cycle

Fig. 17. Reduced fmep development vs. engine cycle for the $10-75 \%$ load increase
Loaded bearings and auxiliaries are mostly dependent on engine speed, whereas the effect of pressures is dominant for the piston rings assembly. This is best highlighted in Fig. 18, which shows the development of the various friction components reduced fmep for the nominal transient load increase of $10-75 \%$.

The dominance of the piston rings assembly is obvious (5 piston rings in total, of which the two oil rings have 6 $\mathrm{mm}$ width each). An increasing loading, i.e. increased fueling, and hence gas pressures throughout the transient event are responsible for the increase of piston rings friction values. The primary mechanism here is the increase of forces $F_{\text {ring }}$ (Eq. (14)) and $F_{\text {thr }}$ (Eq. (17)), although the corresponding values ' $s$ ' of the Stribeck diagram (Eq. (11)) and friction coefficient $\mathrm{f}_{\mathrm{pr}}$ (Eq. (13)) behave in an opposite way.

On the other hand, piston rings friction force generally decreases with a decrease in engine speed due to the lower $u_{\text {pist }}$ values. For the examined transient event, however, the effect of engine speed is minimal owing to the small speed drop observed. All the other friction terms have smaller contribution to the total fmep, especially at the low engine speed under study. This holds, particularly, for the loaded bearings term, which is heavily dependent on engine speed. Only the auxiliaries' friction exhibits a markedly increasing trend during the transient event, due to the significant increase in injected fuel quantity from cycle 15 onwards.

The mean value, over each engine cycle, of the upper piston ring oil film thickness is also provided in the same figure with respect to the engine cycles. This profile follows closely the fuel pump rack position illustrated in Fig. 17. The latter determines the fueling and, thus, the level of in-cylinder gas pressures that mainly affect oil film thickness. Decreasing (mean) oil film thickness is observed throughout the transient event, owing to the harder push of the ring against the liner that originates from the increasing fueling/gas pressures.

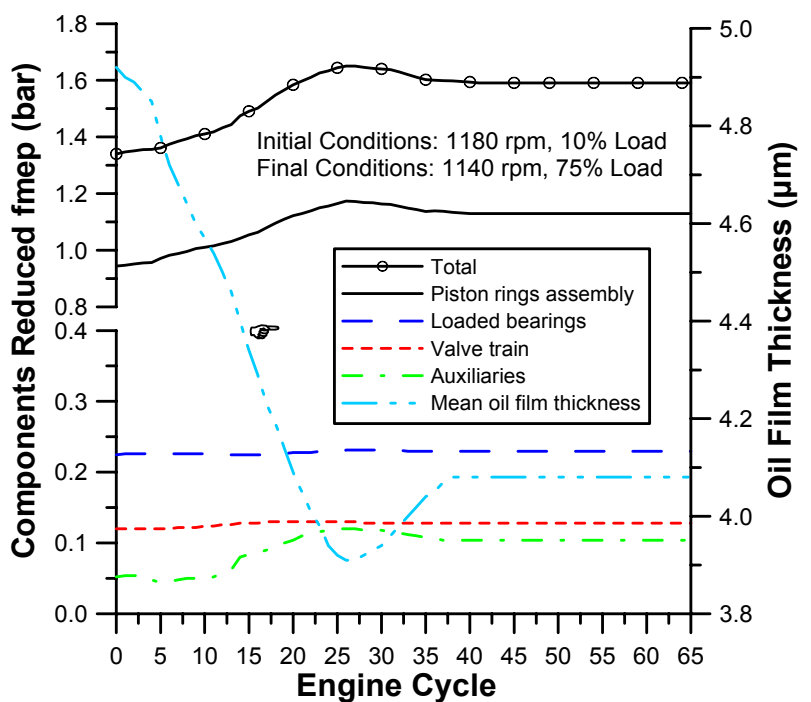

Fig. 18. Reduced components fmep and mean oil film thickness vs. engine cycle for the $10-75 \%$ load increase 
The above results, concerning oil film thickness, are expanded in Fig. 19 that focuses on the development of predicted instantaneous oil film thickness during various engine cycles of the transient load increase of $10-75 \%$. Recall that oil film thickness decreases with increasing in-cylinder gas pressures, due to the harder push of the ring against the liner. Consequently, a reduction is observed in its values as the transient event develops, for as long as the fueling increases. Past research has indicated that increasing engine speed reduces oil film thickness, probably because of viscous heating around TDC that increases oil film temperatures [27,28]. For the present transient event, however, engine speed varies only modestly, hence no conclusion can be drawn regarding the transient response of oil film thickness with engine speed.

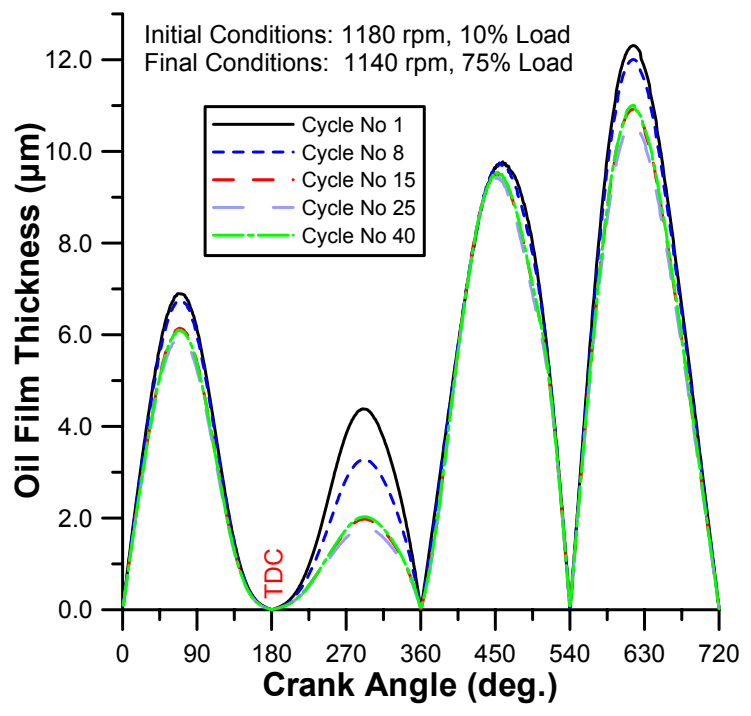

Fig. 19. Oil film thickness development over an engine cycle for various cycles of the $10-75 \%$ load increase

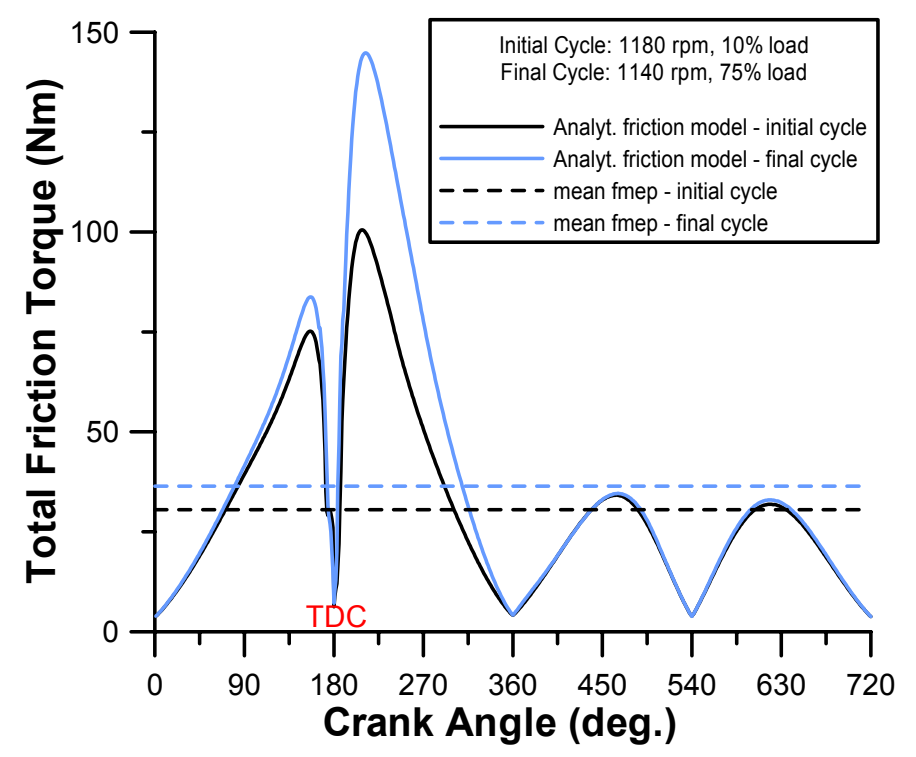

Fig. 20. Total friction torque variation at initial and final cycle of the 10$75 \%$ load increase: Comparison between analytical and constant fmep models for cylinder No 1 of the engine
In Fig. 20 the variation of total friction torque (Eq. (26)) during the first and the last cycle of the nominal transient event of $10-75 \%$ load increase are given, compared to the mean fmep results from Eq. (31). This figure seems to illustrate the importance of detailed friction modeling in the most explicit way. Whereas force is the key parameter for fundamental friction analyses, torque is a property more suitable in transient engine calculations, as this is needed in the crankshaft angular momentum equilibrium. The torque profiles obtained using the detailed model, depicted in Fig. 20, agree with the experimental results given in $[9,18,19]$. The effect of term $\mathrm{u}_{\text {pist }} / \mathrm{r} \omega$ in Eq. (18) is obvious, mainly around firing TDC where the contribution of piston rings is minimized. The last cycle has a much 'fuller' friction torque diagram, despite the somewhat lower engine speed of $1140 \mathrm{rpm}$, originating from higher gas pressures owing to the increased fueling. The main finding is that constant fmep analysis significantly underestimates friction torque for a period of almost $180^{\circ} \mathrm{CA}$ during the last stage of compression, and during expansion when gas pressures are high. This result emphasizes the fact that a detailed friction modeling is needed in transient diesel engine simulations. The underestimation of 'true' friction torque by the fmep relations eventually led to the smaller speed drops observed in Fig. 16.

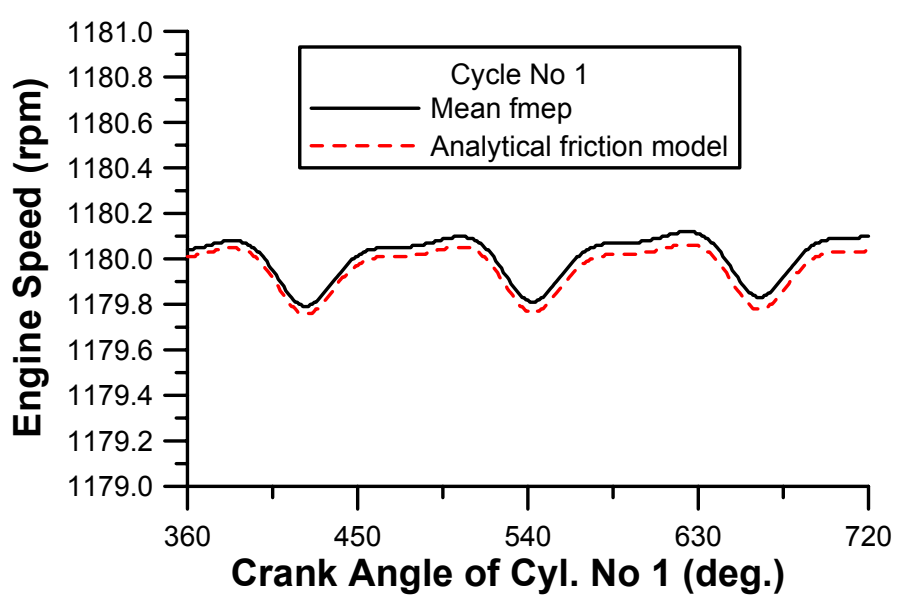

Fig. 21. Engine speed development over the second half of the first cycle of the $10-75 \%$ load increase

The latter finding is supported in Fig. 21, which shows the two predicted engine speed developments (using analytical and constant fmep modeling) during the second half of the first cycle of the transient event, where the load increase commences; the crank angle here corresponds to cylinder No 1. The increased moment of inertia of the engine-brake setup leads to very large engine non-uniformity and, thus, limited speed fluctuations. Nonetheless, the greater speed drops of the detailed friction modeling are already apparent. 


\section{SUMMARY AND CONCLUSIONS}

An experimentally validated transient simulation code developed has been used to: a) study the development of various engine dynamic terms during transients, and b) assess the importance of incorporating detailed dynamic sub-models in the transient simulation code for improved predictions accuracy. An improved understanding of key issues contributing and controlling the various diesel engine dynamic terms during transients is believed to have been accomplished. From the analysis, the following were revealed for the present engine-load configuration:

- Two of the assumptions concerning dynamic modeling, i.e. connecting rod equivalent to two lumped masses, and crankshaft assumed sufficiently rigid, are well justified, as regards accuracy of engine speed response predictions. Hence, their incorporation into a transient simulation code is not necessary, if the accuracy of predictions is the main object of research.

- This does not hold true, however, for the 'mean fmep' relations. Instead, a detailed friction model needs to be incorporated in the transient code. The most significant drawback is the need for many input data that may not always be readily available. The engine under study had a high mass moment of inertia and a narrow speed range, which did not allow great differences to be revealed. Nonetheless, differences of the order of $5-8 \%$ between the detailed friction modeling and the constant fmep approach have been detected for typical load changes; for engine-load configurations of lower total moment of inertia it is strongly suspected that greater differences would occur. This difference is attributed to the fact that constant fmep significantly underestimates actual friction torque, mainly around firing TDC, for a period of almost $180^{\circ} \mathrm{CA}$. In the authors' mind, the application of analytical friction modeling is justified for more accurate transient simulations, provided that an experimental investigation supports the above findings.

- Other important issues concerning friction development during transients are:

1. The contribution of piston rings assembly friction is dominant for the present engine, during both steady-state and transient operation, due to the high number of piston rings and the large width of the two oil rings. Shift from hydrodynamic to mixed lubrication occurs around firing TDC with simultaneous, considerable increase in friction coefficient, owing to the oil film temporarily breaking down. Increased fueling, during the transient event, has led to higher levels of gas pressures and, hence, greater piston rings assembly friction. The development of piston ring friction coefficient over an engine cycle remains practically unaffected by the level of loading/fueling. Piston skirt friction profile closely follows the instantaneous piston speed development, having much smaller contribution to the piston ring pack friction than the piston rings. The overall low crankshaft speed was the main reason for the overall low contribution of the loaded bearings.

2. Oil film thickness was found to acquire almost zero value at firing TDC, with its overall values, over an engine cycle during transients, reducing when fueling was increased, because of the high gas pressures. Its, mean over an engine cycle, profile during a load transient follows closely the fuel pump rack position response.

3. An interesting transient case has been investigated too, with the lower oil temperature leading to higher viscosity and, hence, greater speed drops compared to the nominal fully warmed operation.

- Applying a detailed crankshaft angular momentum equilibrium helped in establishing crankshaft deformation values during transients. Engine torque was identified as the main contributor in crankshaft deformation profile and peak values. Smaller load changes and more rigid construction of the crankshaft were identified as key parameters for reducing the torsional deformation of the crankshaft during transients.

- Bearing loadings depend on gas pressure during the power generation and on inertia forces during the gas exchange process; their maximum values are determined by the peak cylinder pressure, occuring a few degrees CA after firing TDC. The transient profile of maximum bearing loading closely resembles the peak cylinder pressure response. During the period of increasing loading/fueling, high bearing loading rates may be observed. The loading gradually attenuates as we move from the piston towards the crankshaft.

\section{REFERENCES}

1. Watson, N., "Transient Performance Simulation and Analysis of Turbocharged Diesel Engines", SAE Paper No. 810338, 1981.

2. Winterbone, D.E., "Transient Performance", in J.H. Horlock and D.E. Winterbone (eds), The Thermodynamics and Gas Dynamics of Internal Combustion Engines, Vol.Il, Clarendon Press, Oxford, 1986.

3. Woschni, G., Doll, M. and Spindler, W., "Simulation of the Stationary and Transient Performance of Small High Speed Car Diesel Engines", Motortechnische Zeitschrift, Vol. 52, pp. 468-477, 1991 (in German).

4. Wijetunge, R.S., Brace, C.J., Hawley, J.G., Vaughn, N.D., Horrocks, R.W. and Bird, G.L., "Dynamic Behaviour of a High Speed Direct Injection Diesel Engine", SAE Paper No. 1999-01-0829, 1999.

5. Chan, S.H., He, Y. and Sun, J.H., "Prediction of Transient Nitric Oxide in Diesel Exhaust", Proceedings of the Institution of Mechanical Engineers, Part D, Journal of Automobile Engineering, Vol. 213, No. 4, pp. 327-339, 1999. 
6. Rakopoulos, C.D., Giakoumis, E.G., Hountalas, D.T. and Rakopoulos, D.C., "The Effect of Various Dynamic, Thermodynamic and Design Parameters on the Performance of a Turbocharged Diesel Engine Operating under Transient Load Conditions", SAE Paper No. 2004-01-0926.

7. Rakopoulos, C.D. and Giakoumis, E.G., "Review of Thermodynamic Diesel Engine Simulations under Transient Operating Conditions", SAE Paper No. 2006-01-0884, 2006.

8. Heywood, J.B., Internal Combustion Engine Fundamentals, McGraw-Hill, New York, 1988.

9. Richardson, D.E., "Review of Power Cylinder Friction for Diesel Engines", ASME Transactions, Journal of Engineering for Gas Turbines and Power, Vol. 122, pp. 506-519, 2000.

10. Gish, R.E., McCullough, J.D., Retzloff, J.B. and Mueller, H.T., "Determination of True Engine Friction", SAE Transactions, Vol. 66, pp. 649-661, 1958.

11. McGeehan, J.A., "Literature Review of the Effects of Piston Ring Friction and Lubricating Oil Viscosity on Fuel Economy", SAE Paper No. 780673, 1978.

12. Winterbone, D.E. and Tennant, D.W.H., "The Variation of Friction and Combustion Rates during Diesel Engine Transients", SAE Paper No. 810339, 1981.

13. Rakopoulos, C.D. and Giakoumis, E.G., "Prediction of Friction Development during Transient Diesel Engine Operation Using a Detailed Model", International Journal of Vehicle Design, Vol. 43, 2007.

14. Keribar, R. and Morel, T., "Thermal Shock Calculations in I.C. Engines", SAE Paper No. 870162, 1987.

15. Gardner, T.P. and Henein, N.A., "Diesel Starting: A Mathematical Model", SAE Paper No. 880426, 1988.

16. Tuccilo, R., Arnone, L., Bozza, F., Nocera, R. and Senatore, A., "Experimental Correlations for Heat Release and Mechanical Losses in Turbocharged Diesel Engines", SAE Paper No. 932459, 1993.

17. Zweiri, Y.H., Whidborne, J.F. and Seneviratne, L.D., "Detailed Analytical Model of a Single-Cylinder Diesel Engine in the Crank Angle Domain", Proceedings of the Institution of Mechanical Engineers, Part D, Journal of Automobile Engineering, Vol. 215, No. 11, pp. 1197-1216, 2001.

18. Ciulli, E., Rizzoni, G. and Dawson, J., "Numerical and Experimental Study of Friction on a Single Cylinder CFR Engine", SAE Paper No. 960357, 1996.

19. Rezeka, S.F. and Henein, N.A., "A New Approach to Evaluate Instantaneous Friction and its Components in Internal Combustion Engines", SAE Paper No. 840179, 1984.

20. Rakopoulos, C.D. and Giakoumis, E.G., "Sensitivity Analysis of Transient Diesel Engine Simulation", Proceedings of the Institution of Mechanical Engineers, Part D, Journal of Automobile Engineering, Vol. 220, pp. 89-101, 2006.
21. Taraza, D., Henein, N. and Bryzik, W., "Friction Losses in Multi-Cylinder Diesel Engines", SAE Paper No. 2000-01-0921, 2000.

22. Whitehouse N.D. and Way, R.G.B., "Rate of Heat Release in Diesel Engines and its Correlation with Fuel Injection Data", Proceedings of the Institution of Mechanical Engineers, Part 3J, Vol. 184, pp. 17-27, 1969-70.

23. Benson, R.S. and Whitehouse, N.D., Internal Combustion Engines, Pergamon Press, Oxford, 1979.

24. Annand, W.J.D. and Ma, T.H., "Instantaneous Heat Transfer Rates to the Cylinder Head Surface of a Small Compression-Ignition Engine", Proceedings of the Institution of Mechanical Engineers, Vol. 185, pp. 976-987, 1970-71.

25. Lang, O.R., Triebwerke Schnellaufender Verbrennungsmotoren, Springer-Verlag, Berlin, 1966.

26. Taylor, C.F., The Internal Combustion Engine in Theory and Practice, Vol. 2, MIT Press, Cambridge, MA, 1985.

27. Stanley, R., Taraza, D., Henein, N. and Bryzik, W., "A Simplified Model of the Piston Ring Assembly", SAE Paper No. 1999-01-0974, 1999.

28. Ferguson, C.R. and Kirkpatrick, A.T., Internal Combustion Engines: Applied Thermosciences, $2^{\text {nd }}$ Edition, Wiley, New York, 2001.

29. Froelund, K., Schramm, J., Tian, T., Wong, V. and Hochgreb, S., "Analysis of the Piston Ring/Liner Oil Film Development During Warm-Up for an SIEngine", ASME Transactions, Journal of Engineering for Gas Turbines and Power, Vol. 123, pp. 109-116, 2001.

30. Rakopoulos, C.D. and Hountalas, D.T., "A Simulation Analysis of a DI Diesel Engine Fuel Injection System Fitted with a Constant Pressure Valve", Energy Conversion and Management, Vol. 37, pp. 135-150, 1996.

31. Drakunov, S., Rizzoni, G. and Wang, Y.-Y., "On-Line Estimation of Indicated Torque in IC Engines Using Nonlinear Observers", SAE Paper No. 950840, 1995.

32. Rakopoulos, C.D., Giakoumis, E.G. and Hountalas, D.T., "The Effect of Governor Technical Characteristics and Type on the Transient Performance of a Naturally Aspirated IDI Diesel Engine", SAE Paper No. 970633. SAE Transactions, Journal of Engines, Vol. 106, pp. 905-922, 1997.

33. Halsband, M., "Messung und Optimierung der Reibungsverluste der Kolbengruppe - Teil 1', MotorTechnische Zeitschrift, Vol. 55, pp. 664-671, 1994.

34. Cho, M.-R., Oh, D.-Y., Moon, T.-S. and Han, D.-C., "Theoretical Evaluation of the Effects of Crank Offset on the Reduction of Engine Friction“, Proceedings of the Institution of Mechanical Engineers, Part D, Journal of Automobile Engineering, Vol. 217, pp. 891-898, 2003.

35. Radakovic, D.J. and Khonsari, M.M., "Heat Transfer in a Thin-Film Flow in the Presence of Squeeze and Shear Thinning: Application to Piston Rings", ASME 
Transactions, Journal of Heat Transfer, Vol. 119, pp. 249-257, 1997.

36. Chen, S.K. and Flynn, P., "Development of a Compression Ignition Research Engine", SAE Paper No. 650733, 1965.

\section{CONTACT}

Professor C.D. Rakopoulos (cdrakops@central.ntua.gr) and Dr. E.G. Giakoumis (vgiakms@central.ntua.gr): National Technical University of Athens (NTUA), School of Mechanical Engineering, Thermal Engineering Department, 9 Heroon Polytechniou St., Zografou Campus, 15780, Athens, Greece.

\section{DEFINITIONS, ACRONYMS, ABBREVIATIONS}

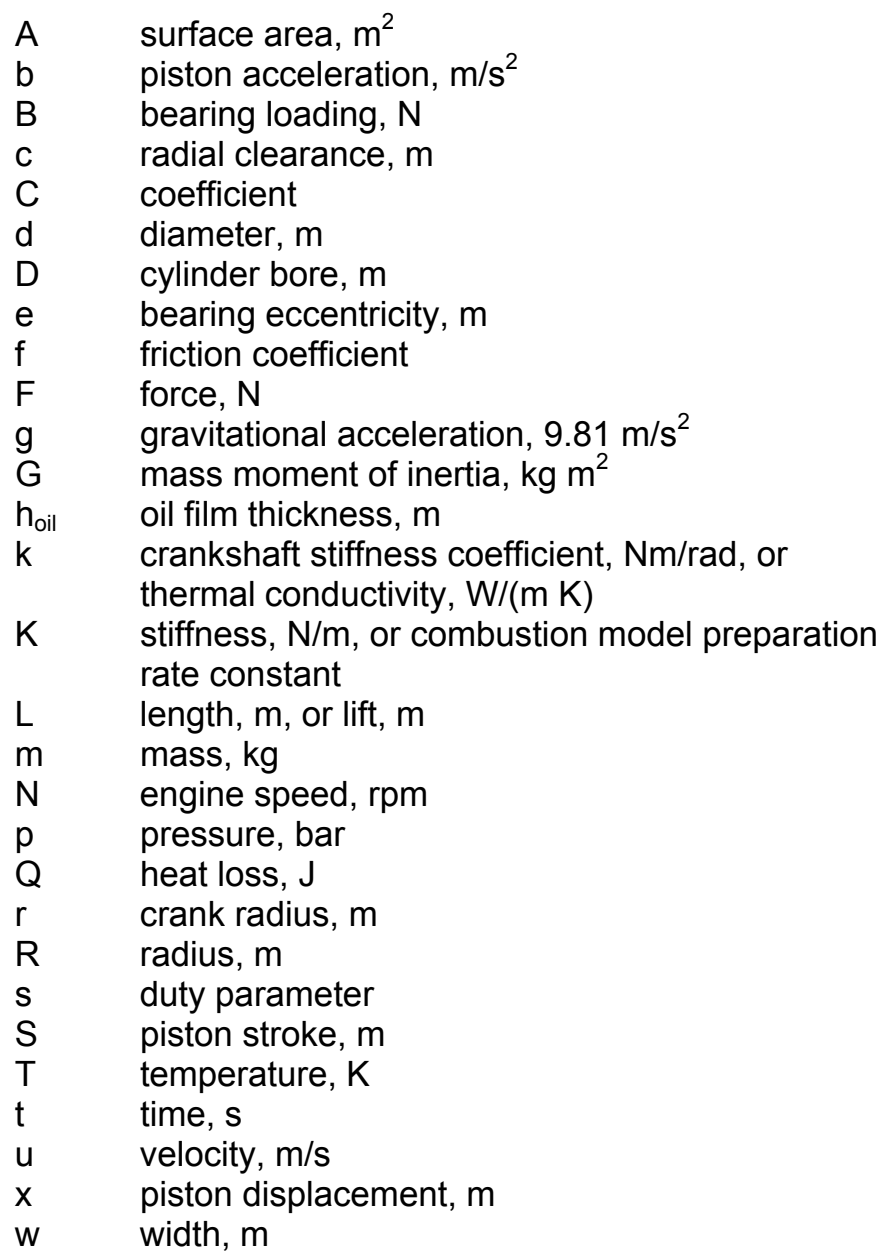

Greek symbols

$\begin{array}{ll}\alpha & \text { bearing eccentricity ratio } \\ \beta & \text { connecting rod angle, deg } \\ \varepsilon & \text { angular acceleration, rad/s } \mathrm{s}^{2} \\ \eta & \text { efficiency, \% } \\ \theta & \text { bearing force angle, deg } \\ \Theta & \text { temperature, }{ }^{\circ} \mathrm{C} \\ \lambda & \text { ratio of crank radius to connecting rod length } \\ \mu & \text { dynamic viscosity, } \mathrm{Ns} / \mathrm{m}^{2} \\ \mathrm{~T} & \text { torque, } \mathrm{Nm} \\ \varphi & \text { crank angle, deg } \\ \Phi & \text { fuel-air equivalence ratio } \\ \omega & \text { angular velocity, rad/s }\end{array}$

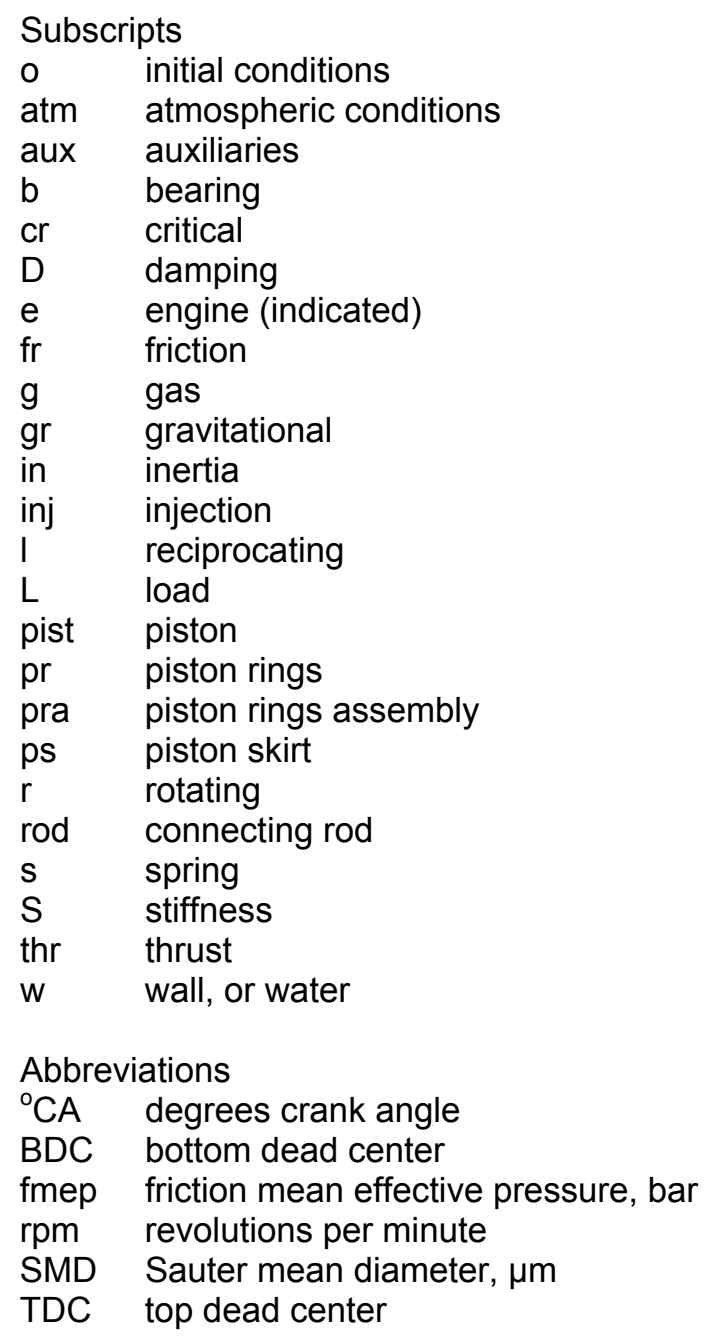

\section{APPENDIX A}

INERTIA FORCES AND MOMENTS - With reference to Fig. A, it holds

$$
\begin{gathered}
L \sin \beta=r \sin \varphi \Rightarrow L \frac{d \beta}{d t} \cos \beta=r \frac{d \varphi}{d t} \cos \varphi \\
\frac{d \beta}{d t}=\omega_{\text {rod }}=\lambda \omega \frac{\cos \varphi}{\left(1-\lambda^{2} \sin ^{2} \varphi\right)^{1 / 2}} \\
\frac{d^{2} \beta}{d t^{2}}=\frac{d \omega_{\text {rod }}}{d t}=\varepsilon_{\text {rod }}= \\
\lambda \omega^{2} \sin \varphi \frac{\lambda^{2}-1}{\left(1-\lambda^{2} \sin ^{2} \varphi\right)^{3 / 2}}+\lambda \varepsilon \frac{\cos \varphi}{\left(1-\lambda^{2} \sin ^{2} \varphi\right)^{1 / 2}}
\end{gathered}
$$

In the above three relations, $\omega_{\text {rod }}$ and $\varepsilon_{\text {rod }}$ are the connecting rod's angular velocity and acceleration, respectively.

With reference to Fig. A, a (moving) frame of reference of orthogonal axes $(n, t)$ is considered, which is 
fixed on the rod, with directions parallel and perpendicular to the rod's axis, respectively; they have components $F_{3}$ and $F_{4}$ of the crankpin force on them, respectively. A balance of all forces acting on the rod, analyzed in $\mathrm{n}$ and $\mathrm{t}$ directions, and a balance of torques with respect to the crankpin axis gives:

n-axis forces:

$$
F_{4}+F_{\text {pist }} \cos \beta+F_{\text {thr }} \sin \beta=F_{\text {rod }}-F_{1} \cos \beta
$$

t-axis forces:

$$
F_{3}-F_{\text {pist }} \sin \beta+F_{\text {thr }} \cos \beta=F_{2}+F_{1} \sin \beta
$$

torques:

$$
\begin{aligned}
& -F_{\text {thr }} \cdot\left(L_{\text {rod }} \cos \beta\right)+F_{\text {pist }} \cdot(r \sin \varphi)= \\
& G_{\text {rod }} \cdot \varepsilon_{\text {rod }}-F_{1} \cdot\left(x_{\text {rod }} \sin \beta\right)-F_{2} x_{\text {rod }}
\end{aligned}
$$

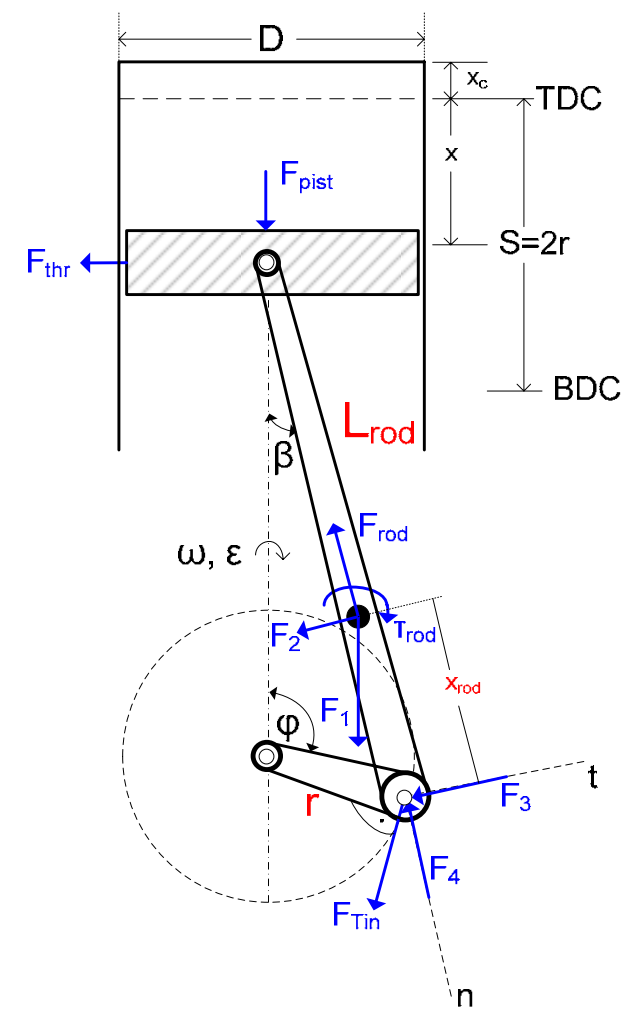

Fig. A. Slider crank mechanism illustrating forces and torques for the computation of total inertia force

In the above equations, torque $T_{\text {rod }}=G_{\text {rod }} \varepsilon_{\text {rod }}$ with $G_{\text {rod }}$ the rod's mass moment of inertia with respect to its center of gravity, $F_{\text {pist }}=-m_{\text {pist }} b$ is the longitudinal force along the cylinder axis acting on the piston assembly to produce its acceleration (piston acceleration $b(\varphi)$ has been defined in Eq. (4b)), and $F_{1}=-m_{\text {rod }} b$ is the force acting on the connecting rod center of gravity due to the linear acceleration of the piston. Also, $F_{2}=m_{\text {rod }}(L-$ $\left.\mathrm{X}_{\text {rod }}\right) \varepsilon_{\text {rod }}$ and $F_{\text {rod }}=m_{\text {rod }}\left(L-X_{\text {rod }}\right) \omega_{\text {rod }}^{2}$, with $\left(L-X_{\text {rod }}\right) \varepsilon_{\text {rod }}$ the tangential component and $\left(L-x_{\text {rod }}\right) \omega_{\text {rod }}^{2}$ the normal component of the rod's center of gravity acceleration with respect to the piston pin. Further, in the above equations, $x_{\text {rod }}$ is the distance between the rod's center of gravity and the crankpin axis.

The system of equations (A4), (A5) and (A6) can be solved for the unknown forces $F_{\text {thr }}, F_{3}$ and $F_{4}$. Force $F_{\text {thr }}$ is the thrust force acting by the piston on the side wall of the cylinder. The sum of the projections of forces $F_{3}$ and $\mathrm{F}_{4}$ on an axis perpendicular to the crank radius produces the tangential (inertia) force $F_{T i n}$, due to the inertia of the moving parts (piston assembly and connecting rod) acting on the crank, i.e.

$$
\left.F_{\text {Tin }}=F_{3} \cos (\varphi+\beta)+F_{4} \sin (\varphi+\beta)\right)
$$

The latter is used in Eq.(28) for the computation of the engine indicated torque.

\section{APPENDIX B}

Data and constants for the application of mean and analytical friction models are provided below.

Mean fmep method - Eq. (30)

$-\alpha=0.111$

$-\beta=0.004$

$-\gamma=0.1136$

Analytical model - Eqs (11)-(26)

- Number of compression rings $=3$

- Number of oil rings $=2$

- Compression ring width, $\mathrm{w}_{\mathrm{c}}=3.5 \mathrm{~mm}$

- Oil ring width, $\mathrm{w}_{\mathrm{o}}=6 \mathrm{~mm}$

- Length of piston skirt, $L_{p s}=152.5 \mathrm{~mm}$

- Main crankshaft bearing

Radius, $\mathrm{R}_{\mathrm{jb}}=57.5 \mathrm{~mm}$

Radial clearance, $\mathrm{c}_{\mathrm{jb}}=0.135 \mathrm{~mm}$

Length, $L_{\mathrm{jb}}=52 \mathrm{~mm}$

- Connecting rod big end bearing

Radius, $\mathrm{R}_{\mathrm{cr}}=49.8 \mathrm{~mm}$

Radial clearance, $\mathrm{c}_{\mathrm{cr}}=0.135 \mathrm{~mm}$

Length, $\mathrm{L}_{\mathrm{cr}}=62.0 \mathrm{~mm}$

- Valve spring preloading force, $F_{o}=360 \mathrm{~N}$

- Spring stiffness, $K_{s}=25,000 \mathrm{~N} / \mathrm{m}$

- Mean oil temperature, $\Theta_{\text {oil }}=90^{\circ} \mathrm{C}$

- Crank radius, $r=90 \mathrm{~mm}$

- Maximum valve lift, $L_{v}=12.5 \mathrm{~mm}$

- Arm ratio, $A_{R}=1$

- Cam width, $\mathrm{L}_{\text {cam }}=33 \mathrm{~mm}$

SAE 30 oil constants - Eq. (12)

$-\mathrm{C}_{\text {oil }}=0.0246 \mathrm{mPa} \mathrm{s}$

$-\Theta_{1}=1432.3^{\circ} \mathrm{C}$

$-\Theta_{2}=132.9^{\circ} \mathrm{C}$ 